\title{
BARCELONA: HAEC OMNIA - DIVISA - TIBI DABO... COHESIÓN Y DIVISIÓN EN LA EVOLUCIÓN (GEO)URBANA DE UNA CIUDAD AMBIVALENTEMENTE COMPACTA
}

\author{
Manuel Gausa Navarro
}

Dipartimento di Architettura e Design, Unige, Università degli Studi, Genova, Italia, gausa@coac.net

\section{RESUMEN}

Desde la cima del Tibidabo Barcelona se ha presentado, durante muchos años, como un Todo unitario (haec omnia tibi dabo... Todo esto te daré, Mateo 4:9): una masa compacta, sensiblemente regular, extendida entre los dos ríos laterales y el mar (los límites que, en el pasado, habían delimitado su geografía). Incluso con el salto de escala reciente Barcelona ha conservado su aparente claridad estructural, a pesar de los procesos difusos que han caracterizado estas últimas décadas. Sin embargo, bajo esa aparente "unidad/uniformidad", civil y cívica, Barcelona ha sido siempre una ciudad dividida, tanto en lo físico como en lo social. Lo más sorprendente de esa división es su carácter sistémico a lo largo del tiempo, al coincidir -en cada periodo- "división sociocultural" y "división física” en ciertos espacios de límite claramente reconocibles en la propia estructura urbana y en su propio desarrollo (desde la ciudad romana y medieval hasta la ciudad industrial y postindustrial o la ciudad informacional contemporánea).

En este texto se revisan diversos ejemplos suficientemente explícitos en los que la paradójica ecuación unidad-división ha marcado la historia (mesuradamente contradictoria y dual) de una ciudad abierta y cerrada, doméstica y cosmopolita, liberal y conservadora, ambiciosa y temerosa, emprendedora y auto-referencial; una ciudad en la que, en sus mejores momentos, las dos caras de la moneda -los conocidos seny (sentido común) y rauxa (rabia emocional)- habrían dejado paso a una tercera vía, la empenta (el empuje, racional y creativo) capaz de superar solercias e inercias, convenciones, y divisiones.

Palabras clave: Estructura urbana, entre-lugares, redes y enlaces, multi-ciudades, geourbanidades 


\section{ABSTRACT}

From the top of Tibidabo, Barcelona has presented itself, for many years, as a unitary Whole (haec omnia tibi dabo ... All this I will give you, Matthew 4: 9): a compact mass, sensibly regular, extended between the two lateral rivers and the sea (the limits that, in the past, had delimited its geography). Even with the recent leap in scale, Barcelona has preserved its apparent structural clarity, despite the diffuse processes that have characterized these last decades.

However, under that apparent "unity / uniformity", civil and civic, Barcelona has always been a divided city, both physically and socially. The most surprising thing about this division is its systemic character over time, as "sociocultural division" and "physical division" coincide -in each period- in certain boundary spaces that are clearly recognizable in the urban structure itself and in its own development (from the Roman and medieval city to the industrial and post-industrial city or the contemporary informational city).

In this text several sufficiently explicit examples are reviewed in which the paradoxical unit-division equation has marked the history (moderately contradictory and dual) of an open and closed city, domestic and cosmopolitan, liberal and conservative, ambitious and fearful, entrepreneurial and self -referential; a city in which, in its best moments, the two sides of the coin -the well-known seny (common sense) and rauxa (emotional rage)- would have given way to a third way, the empenta (the drive, rational and creative) capable of overcoming abilities and inertias, conventions, and divisions.

\section{Key words: Urban structure, in-between-plac- es, networks and links, multi-cities, geo-ur- banities}

\section{RESUMO}

Do alto do Tibidabo, Barcelona se apresentou, por muitos anos, como um Todo unitário (haec omnia tibi dabo ... Tudo isso Vou te dar, Mateus 4: 9): uma massa sensível, compacta e regular, estendida entre dois rios laterais e o mar (os limites que, no passado, delimitaram sua geografia). Mesmo com o recente salto de escala e apesar dos processos difusos que caracterizaram estas últimas décadas, Barcelona tem preservado sua aparente clareza estrutural. No entanto, sob essa aparente "unidade / uniformidade", civil e cívica, Barcelona sempre foi uma cidade dividi$\mathrm{da}$, tanto física como socialmente. O mais surpreendente aspecto desta divisão, ao longo do tempo, é o seu carácter sistémico, uma vez que em cada período coincidem, em determinados espaços de fronteira, a "divisão sociocultural" e a "divisão física”, espaços esses claramente reconhecíveis na estrutura urbana e em seu próprio desenvolvimento - desde a cidade romana e medieval à cidade industrial e pós-industrial, ou ainda à cidade informacional contemporânea.

Neste texto, são revisados exemplos suficientemente explícitos da paradoxal equação unidade-divisão, que marcou a história de forma moderada, contraditória e dual: de uma cidade aberta e fechada, doméstica e cosmopolita, liberal e conservadora, ambiciosa e temerosa, empreendedora e auto-referencial; uma cidade em que, nos seus melhores momentos, as duas faces da moeda - o bem conhecido seny (senso comum) e rauxa (fúria emocional) - teriam dado lugar a uma terceira alternativa, o empenta (a pulsão, o racional e criativo) capaz de superar habilidades e inércias, convenções e divisões.

Palavras-chave: Estrutura urbana, entre-lu- 
gares, redes e conexões, multi-cidades, geo-urbanidades

Concordia parvae res crescunt, discordia maximae dilabuntur (En concordia las cosas pequeñas crecen; en desunión, las más grandes se derrumban). Sallustio, Bellum Lugurthinum.

\section{VERTICAL-HORIZONTAL: MARCO GEOGRÁFICO. IZQUIERDA-DERECHA, ARRIBA-ABAJO}

LA BARCELONA, ENTRE FRONTERAS; UNA DESCRIPCIÓN BÁSICA... Y BASILAR

$41^{\circ} 16^{\prime}$ y $41^{\circ} 30^{\prime}$ norte de latitud y entre los $1^{\circ}$ $54^{\prime}$ y $2^{\circ} 18^{\prime}$ este de longitud. Levante, Costa Mediterránea

Durante largo tiempo el espacio físico sobre el se extendería la tradicional estructura de Barcelona iba a caracterizarse por la particular posición de sus límites naturales: al Este y al Oeste los lechos de los ríos Besós y Llobregat, pasos naturales de entrada a la ciudad; al Sur la "línea de mar", límite inferior urbano; al Norte, la sierra de Collserola, la "línea de Montaña", constituida en barrera natural para el desarrollo de la ciudad y que presentaría en la cima del Tibidabo (516,2 mts.) su punto más alto.

Entre la línea de mar y la de la montaña, el gran llano, una amplia extensión interrumpida por escasos accidentes: el rosario de promontorios desplegados a los pies de Collserola y los dos montes próximos al mar: Montjuic -una emergencia aislada sobresaliendo abruptamente frente a la costa- y el antiguo "Mons Taber", una pequeña colina, sobre la que iban a establecerse los primeros núcleos de población.
La plana de Barcelona aparecía, así, como un territorio singular y privilegiado de la costa catalana, favorecido por la particular combinación de líneas y franjas paralelas al Mediterráneo: la larga Sierra de Collserola y la sucesión en rosario de siete pequeños promontorios que (como las siete colinas de Roma) se sucedían ritmados, al pie de la gran montaña -Modolell (Sant Gervasi), Monterols (Sant Gervasi), El Putxet (Sant Gervasi), el Carmelo (Gràcia), Santa María del Coll (Gràcia), el Turó de la Rovira (Guinardó) i el Turó de la Peira (Horta)- dejaban paso, a continuación, al propio llano central: éste se extendía hacia el mar con una pendiente prácticamente uniforme hasta la aparición de un amplio cambio de rasante de unos 20 metros de altura (delimitado por la actual Gran Vía y sensiblemente apreciable, todavía hoy, en las bajadas de Puerta del Ángel, Vía Laietana y Calle Jonqueras) producido por las diferencias de basamentos: granitos y pizarras paleozoicos hasta entonces y capas de aluvión hídricas, en esa una nueva superficie plana, en forma de embudo en $\mathrm{V}$ (limitada por Montjuic, a un lado y por la confluencia del Besós al otro) que iba a configurar, de modo natural, una geometría prácticamente similar a la que posteriormente -de manera artificialiban a definir los trazados de las Avenidas del Paralelo y Meridiana sobre la trama de la ciudad (Gausa et al. 2013).

En este sentido, la presencia de esa gran superficie de doble pendiente, surcada de líneas perpendiculares al litoral, iba a favorecer una primera orientación urbana "en vertical”, reforzada posteriormente en la propia retícula del Pla Cerdà, aparentemente isótropa y, no obstante, sensiblemente "vectorizada" hacia el mar. 


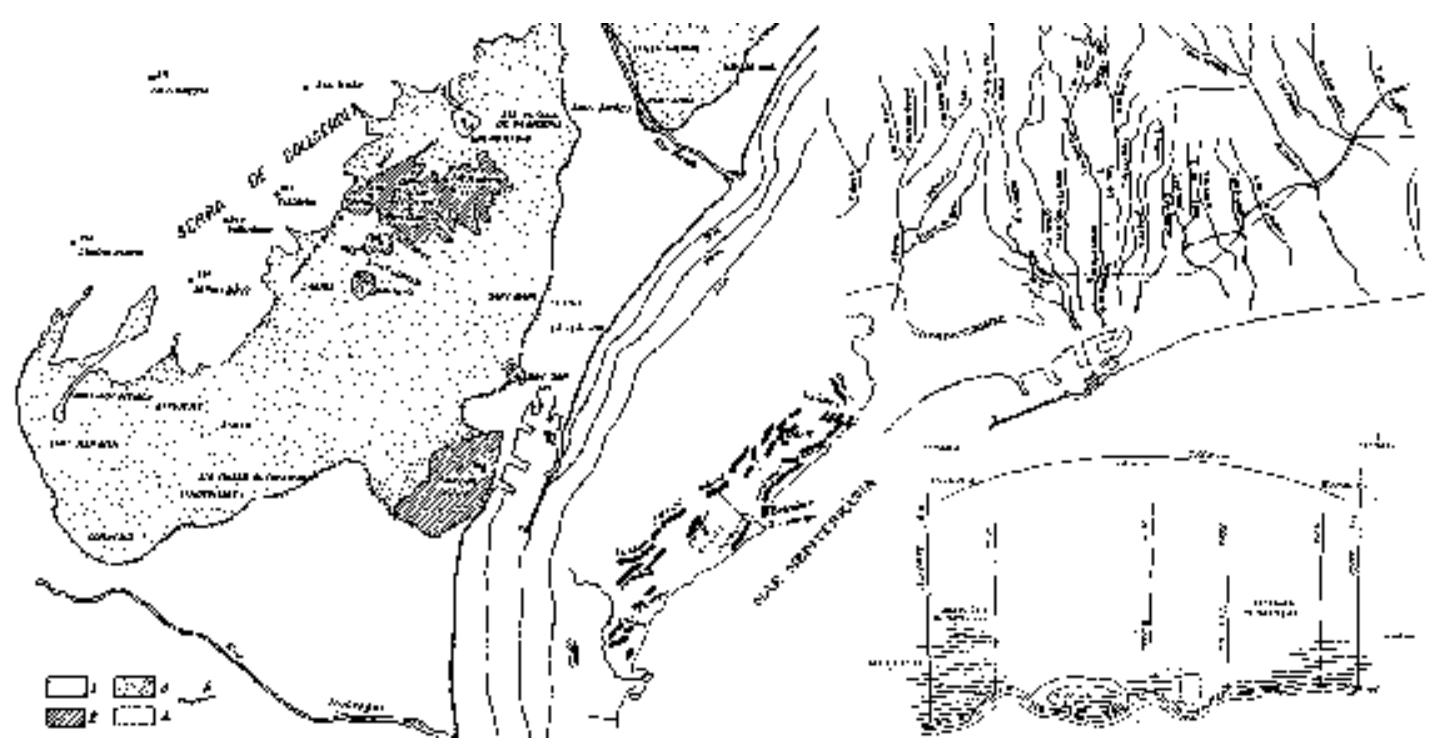

Fig1. De izquierda a derecha: Conformación geológica de Barcelona y su llano y principales alineaciones en sierras y cadenas del litoral, así como primitiva red hidrológica del Barcelonés, según Cassases y Vila, Barcelona i el Seu Plà. Antiguo diagrama con la posición de Montjuic y el Mons Taber y su relación con la red hidrológica, la Montaña y el Mar (en Gausa, Cervelló, Plà, Devesa, Barcelona Guía de Arquitectura Moderna, 2013)

Al mismo tiempo, la situación estratégica de esa Gran Vía “horizontal”, en el Ensanche, no sólo iba a permitir atravesar la ciudad de lado a lado, sino que iba a trazar una especie de virtual división mnemo-territorial, asociada a esa configuración geológica primitiva entre la Barcelona Mar, la Barcelona Centro y la Barcelona montaña, de tan importantes repercusiones en la propia evolución de un municipio largo tiempo encerrado en y entre sus fronteras naturales y que, sin embargo, se proyecta hoy más allá de sus antiguos límites, en un virtual salto de escala "urbano-territorial" que precisa una renovada mirada e interpretación.

\section{LA CRUZ Y LA DAGA: LA BARCINO ROMANA Y LA BARCHINOVA MEDIEVAL \\ LOS CUADRANTES RETICULARES, EL CASCO HISTÓRICO, LA RAMBLA Y EL ARRABAL. ARRIBA-ABAJO, DERECHA- IZQUIERDA}

Cuando en el momento de su refundación la groma y la plomada romanos señalan, en el Mons Taber, el punto de cruce entre el Cardo y el Decumano (los ejes que iban a definir el desarrollo fundacional de la nueva Barcino), la ciudad iba a quedar dividida por esa cruz basilar destinada a estructurarla en cuatro grandes cuarteles o segmentos cuadrangulares (quarters, quatieri, quartiers, barrios o barris) organizados, a su vez, en una serie de retículas más o menos regulares y recursivas entre sí. 
Aunque, desde el siglo IV antes de Cristo, ya existía una antigua comunidad Íbera -Barkeno- posteriormente colonia cartaginesa (Barci Nova, en honor a Amilcar Barca) es en tiempos de Augusto, en el siglo I antes de Cristo, cuando se decide refundar la ciudad: el lugar elegido es, en efecto, una pequeña elevación cerca de la costa, de fácil defensa y con un excelente control sobre el mar y sobre el gran llano extendido hacia la larga que lo enmarcaba al fondo.

Esta primera ciudad amurallada iba a contar con una superficie de apenas trece hectáreas, menores que las sesenta de Tarraco (capital de la Hispania Cisterior) y una población de unos 3500 a unos 5000 habitantes.

La importancia geográfica de esa nueva Barcino, concebida desde el inicio con cierto empaque monumental, iba a radicar principalmente en la ubicación de su puerto natural, perfectamente conectado con las grandes vías de comunicación territorial. En efecto, en el puerto marítimo de Barcino iban a coincidir no sólo la Via Augusta sino los caminos provenientes de las grandes planas agrícolas de Auso (Vic) e Ilerda (Lleida), así diversas vías secundarias. A pesar de la capitalidad de Tarraco la gran movilidad que aseguraba la Via Augusta en toda el área del barcelonés (gracias a la combinación de transportes marítimos, fluviales y terrestres) explicaría el importante papel estratégico e intercambiador de ese puerto y colonia comercial convertido pronto en un polo nodal que dejaba intuir su posterior y destacado rol atractor central (Ariño, Gurt y Palet 1994, 2004; de Soto y Carreras 2007).

La primera muralla de la ciudad poseía pocas torres, solo en los ángulos y en las puertas del propio perímetro amurallado, de $1,5 \mathrm{kms}$. de longitud. Tras las primeras incur- siones de francos y alamanes (a partir de los años 250) ésta se reforzó y amplió con un muro doble de 2 metros de ancho, punteado por 74 torres de vigilancia.

En su interior la ciudad seguía un trazado ortogonal, con manzanas cuadradas o rectangulares, siguiendo una disposición que partía de los dos ejes principales, con una distribución "horizontal" (noroeste- sudoeste) y otra "vertical" (sudeste-nordeste). En su centro, el forum o ágora central, se situaba en la confluencia entre el cardus maximus (hoy calles Llibreteria y Call) y el decumanus maximus (hoy calles Obispo, Ciudad y Regomir) en un eje algo desplazado hacia el Norte (Prieto 2017).

A pesar de la aparente isotropía de la propia retícula, la propia cruz central iba a crear, desde el inicio, una división implícita, largo tiempo presente en la propia memoria urbana.

- Por un lado el cardo (el eje más corto y "paralelo" al mar) iba a recoger, a lado y lado, la entrada de las grandes vías y calzadas territoriales de acceso a la ciudad, atravesándola por la parte más alta de la propia colina y dividiendo así el casco urbano entre la zona Norte (algo más corta, frente al gran plano central y los acueductos perpendiculares que abastecían la ciudad, con una mayor presencia monumental) y la zona Sur (frente al puerto, con una vocación más comercial, artesanal y marinera)

- Por otro lado el eje central o Decumano iba a dividir la estructura urbana en dos lados diferenciados a su vez: el derecho (orientado hacia los terrenos más abiertos y agrícolas que flanqueaban el río Besós) y el lado izquierdo marcado por la presencia, junto a la muralla, de 
las marismas limosas y pantanosas del torrente tangencial que posteriormente -en época árabe-iba a denominarse Rambla (Ramlah, en árabe antiguo) así como por los diversos lechos inestables de los arroyos próximos y la emergencia cercana de la montaña de Montjuic.

Los numerosos fragmentos escultóricos encontrados en la parte derecha, la probable presencia de diversos templos y "Domus" o la importancia de restos de estructuras comerciales y agrícolas indicaría como, mientras dicho lado poseería un carácter más privilegiado, el segundo evidenciaría la presencia de tejidos socio-estructurales más secundarios o de "servicios", como tabernas, termas públicas o algunos lupanares, situados en una ubicación aparentemente menos atractiva como señalaría la presencia (redescubierta en 1954) de las necrópolis próximas a la Rambla.

Esa división entre sectores Mar/Montaña-Norte/Zona Superior y Sur/Zona Inferiorpero, sobre todo, entre Lado Izquierdo y Lado Derecho iba a marcar el propio "genoma urbano" de Barcelona y muchas de sus posteriores dinámicas y evoluciones, rompiendo en efecto, desde el inicio, la aparente regularidad abstracta de una cuadrícula teóricamente homogénea (derivada de los propios campos militares romanos o de los sistemas de centuriato agrícolas, destinados a estructurar los propios campos de cultivo y colonización y muy presentes, por otra parte, en la Cataluña romana).

De hecho, en un salto de escala "quasifractal", el mismo tipo de situación curiosamente disotrópica se iba a crear en la propia malla reticular característica de las vías destinadas a estructurar el territorio catalán. La propia morfología geográfica de la futura Catalunya iba a fa- vorecer esa organización en red, con dos grandes grupos de calzadas entrecruzadas, relacionadas según su propia orientación: en un primer conjunto la "trama" de los dos grandes ejes transversales, paralelos a la costa en dirección E-O y que aprovechaban los grandes corredores naturales del litoral, el pre-litoral y el interior comunicándolos con el resto de la península por Zaragoza (Caesar Augusta) o Saguntum; en un segundo grupo la "urdimbre" de toda una serie de vías de carácter más secundario, destinadas a comunicar las zonas de los Pirineos y del interior con la propia costa, aprovechando los corredores de los propios cursos fluviales N-S. (Ariño, Gurt y Palet 1994, 2004; de Soto y Carreras 2007).

Ese entramado, bastante insólito, de vías cruzadas en dos direcciones paralelas o perpendiculares a la costa, (deformado ligeramente -dada la propia morfología geográfica del país- en una configuración sensiblemente triangular) tendería a cubrir la mayor parte del territorio y que, en ciertos sectores, se reiteraría de modo mucho más denso e intenso -más tupido o compacto- a escala local (Ariño, Gurt y Palet 1994, 2004; de Soto y Carreras 2007). En efecto, una de las características particulares de dicha configuración en red residiría en la complejidad relacional e intercambiadora entre núcleos y poblaciones de la propia estructura, regular y diferencial a la vez, lejos de otras estructuras más jerarquizadas (radiales o en árbol) que tenderían a observarse en otras provincias como Britannia, por ejemplo.

En todo caso, tras la caída del Imperio romano se sucedieron diversos períodos marcados por la reutilización de la propia ciudad romana y el aprovechamiento de su estructura básica, cada vez más densificada y fragmentada en su interior (Prieto 2017). 
Durante el siglo XI, el Condado de Barcelona, capital de la Marca Carolingia y futuro núcleo de la corona de Aragón iba a convertirse en el principal centro político, económico, social y comercial del país.

La creciente creación de nuevos asentamientos desarrollados principalmente entorno a iglesias y conventos "extramuros", ubicados mayoritariamente en el lado derecho del recinto romano, iba a acabar obligando a ampliar el propio núcleo amurallado (Prieto 2017). Un primer perímetro (iniciado en el siglo XIII bajo Jaume I, 1268) se iba extender durante unos 5 kilómetros, rodeando los nuevos asentamientos y dejando un frente abierto al mar destinado a favorecer el movimiento portuario y el tráfico marítimo. Su trazado delimitaba un área de unas 131 hectáreas y multiplicaba por diez la extensión de la ciudad romana. En su interior seguía perviviendo el Call, un barrio judío con dos sinagogas fundado en 692 y situado, de hecho, en el lado izquierdo de la ciudad romana (entorno a las actuales calles Banys Nous, Palla y Bisbe) separado del resto del centro urbano por sus propios muros y que iba a pervivir hasta su destrucción xenófoba en 1391 (Prieto 2017).

El nuevo recinto ampliaba pues la ciudad hacia la parte derecha, consolidando el límite de la Rambla con un gran muro paralelo a su cauce, con ocho puertas entre las que se encontraban puntos todavía de relevancia en la actualidad como los de Portaferrissa o Boquería.

En el s. XIV (en época de Pere el Cerimoniòs) se inicia la construcción de una nueva muralla destinada a rodear Barcelona por poniente, afín de englobar los asentamientos espontáneos y los huertos agrícolas, así como las instituciones religiosas ubicados fuera del ante- rior recinto amurallado, en el Raval (o "arrabal" en catalán)

Con el trazado definitivo del nuevo perímetro medieval y su característica forma de diamante pentagonal el muro de la Rambla iba a quedar dentro del recinto de la ciudad, dividiendo como una daga (jamhiya, en árabe) su propio tejido urbano (Prieto 2017).

La Rambla iba a constituir, en efecto, un claro límite -físico y virtual- entre la primera ciudad "asentada" (en su lado derecho, más próspero y consolidado) y el confuso arrabal del lado izquierdo (más suburbial): una división explícita y presente, durante varios siglos, intramuros.

En efecto, el propio entramado urbano desarrollado durante toda la época medieval iba a significarse por la presencia de diversas áreas y sectores diferenciados con una influencia diversa; escenarios asociados a la nobleza, al poder institucional, al obispado o las órdenes religiosas, a los gremios artesanales y comerciales o a las clases más menestrales o campesinas. La antigua retícula romana había dejado paso a un denso e intrincado laberinto de subdivisiones y calles irregulares, con plazoletas que apenas eran meros ensanchamientos (o derribos contingentes) de alguna vivienda. Un entramado puntuado por edificios de mayor envergadura (iglesias o palacios, junto a algunas edificaciones institucionales (como la Casa de la Ciutat, sede del Consell de Cent o el Palau de la Generalitat, además de algún hospital -como el de la Santa Cruz- o edificios como el de la Lonja o las Atarazanas). Sin embargo, ya en 1209 iba a darse una de las primeras operaciones urbanísticas privadas de la ciudad: la apertura de la calle de Montcada (gracias a la concesión realizada por Pedro II a Guillem de Montcada) de una vía amplia y rectilínea hacia el mar, ocupada por grandes re- 
sidencias y palacios señoriales. También de esa época sería la apertura de la plaza Nueva, junto al Palacio Episcopal y la catedral de Barcelona, realizada en 1355 . Ambas operaciones iban a caracterizar con fuerza el posteriormente denominado "Barrio Gótico", situado precisamente en el sector derecho, más potente y representativo.

Mientras tanto, en el lado izquierdo de la Rambla, el arrabal o "Raval" iba a seguir manteniendo durante largos años su carácter para-rural, agrícola y suburbano en el interior de la ciudad perimetrada. Campos o espacios de cultivo destinados a garantizar la subsistencia en tiempos de guerras convivían con establecimientos, servicios y actividades más molestas o poco recomendables (desde hospitales y hospicios para pobres hasta tabernas y casas de placer, junto a grandes conventos y edificios
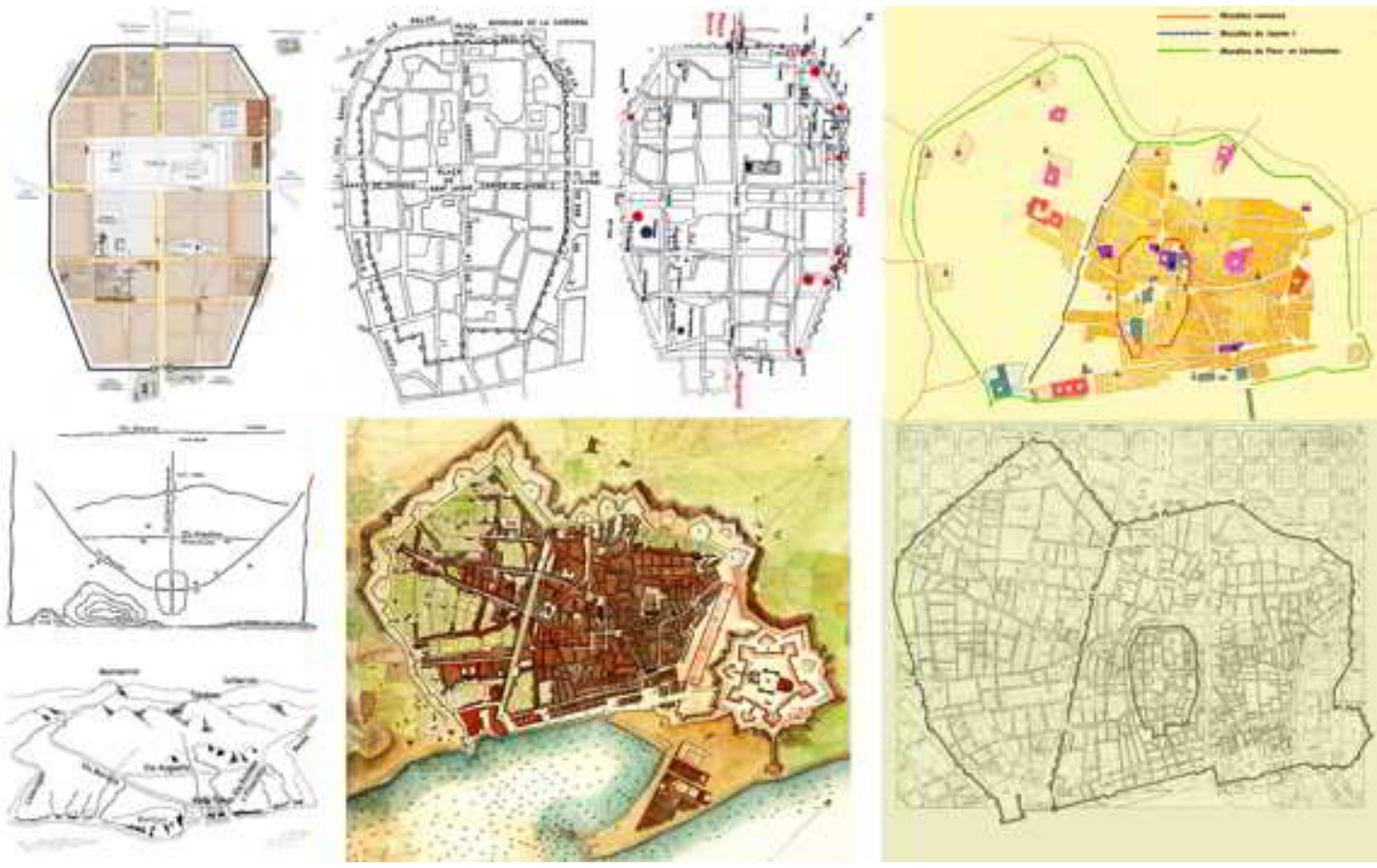

Fig 2. Barcelona: muros y murallas, limes y límites, cruces y "cruceras": Arriba, de izquierda a derecha: reconstrucción de la planta de la ciudad romana con la Cruz Central (cardo y Decumano) y la cuadrícula basilar (hipótesis de J, Beltrán de Heredia, Dibujo de E. Revilla) / Planta de la ciudad amurallada romana en el siglo IV y reconstrucción con la localización de restos de importancia arqueológica (M. Claveria, I. Rodà, Esculturas e inscripciones del entorno de Barcino) / Diagrama de las diferentes murallas romana y medievales representados en colores diversos (en Prieto, G. 2017. La evolución del mapa de Barcelona a través de los siglos)

Abajo, de izquierda a derecha: Antiguos diagramas de las vías que atravesaban el plano de Barcelona en época romana, en Durán Sanpere, 1972. Barcelona i la seva historia. Barcelona: Curial / Mapa de Barcelona en 1806 de Jacques Moulinier, en el que se aprecia todavía el carácter periurbano del Raval y la presencia de la Rambla, como eje y división central (Fuente: ICC) / Plano de la trama de Barcelona con la superposición de los perímetros amurallados y la clara delineación del gran muro de la Rambla/Ramlah y de su curso como penetración -o Daga o jamhiya- de división central (archivo). 
eclesiásticos, muchos de ellos volcados a labores caritativas. Una mezcla promiscua que iba a perpetuarse desde el siglo XIV hasta el s. XIX y el inicio de la revolución industrial.

Es en ese entorno de campos y descampados donde, desde finales del siglo XVIII, las primeras industrias manufactureras empiezan a instalarse en medio de huertos, conventos y casas artesanas (muchas al margen de los gremios "oficiales", radicados en la parte derecha de la ciudad). Y es precisamente entre 1776 y 1778 (bajo Carlos III) cuando se procede al derribo del gran muro interior de la Rambla, con una realineación de los edificios de fachada y el diseño del característico espacio arbolado con salón central, para paseo y, sobre todo, para eventuales desfiles militares.

La primera revolución industrial y sus consecuencias urbanísticas se manifiestan con fuerza, sobre todo en el Raval, conllevando la aparición de nuevas calles con almacenes, fábricas y viviendas -y sub-viviendas- para los trabajadores y campesinos huidos del hambre del campo y desplazados hacia una ciudad que, con un claro "efecto llamada", se presentaba como un destino cada vez más pujante y atractivo. Muchos de los trabajadores de las fábricas iban a vivir cerca de las factorías, en un barrio pronto convertido en el más denso de Europa y en el que -dentro sus límites- se aprovechaba hasta el último metro cuadrado edificable.

El auge industrial, las revueltas sociales y las deficitarias condiciones de vida, así como las frecuentes epidemias de cólera y tifus dentro de la ciudad histórica, iban a favorecer la decisión, en 1859, de derribar las murallas medievales (una reivindicación ampliamente reclamada por la ciudadanía y la nueva burguesía) permitiendo una nueva expansión urbana fuera de un núcleo cada vez más conflictivo, asociado a un movimiento obrero que empezaba a organizarse ya en asociaciones y sindicatos. Con la construcción del Eixample Cerdà -y a pesar del éxodo empresarial hacia otras zonas de la nueva Barcelona- el Raval siguió, sin embargo, ocupando una situación "periférica" como barrio residencial de perfil principalmente obrero, "bohemio" y/o "canalla" al mismo tiempo. Un barrio "a la izquierda", de viviendas para las clases con menor poder adquisitivo, entre las cuales muchas provenientes de la inmigración proveniente de otras regiones de España.

\section{EL CUADRADO, EL ARCO Y LA FLECHA. LA BARCELONA INDUSTRIAL. ENSANCHE DERECHO, ENSANCHE IZQUIERDO Y ENSANCHE CENTRAL. ZONA ALTA, ZONA MEDIA Y ZONA BAJA}

La aprobación, en 1860, del "Plan de Reforma y Ensanche de Barcelona" iba a sintetizar un periodo de la ciudad marcado por las consecuencias de la revolución industrial y caracterizado por una voluntad de expansión, económica, cultural y social y, sobre todo, física. Producto de una laboriosa negociación con el Gobierno central destinada a obtener la autorización para el crecimiento de la ciudad y la superación del "recinto dentro del precinto", el nuevo Plan presentado en 1859 por Ildefons Cerdà por encargo del Gobierno Central, iba a permitir colonizar la amplia llanura que se extendía entre la vieja ciudad amurallada -hiper-densificada y cada vez más insalubre y agresiva- y los núcleos urbanos desarrollados en un gran arco a su alrededor y separados por la distancia preceptiva 
de 1,25 kilómetros (1500 varas castellanas) obligada por las ordenanzas militares (Gausa et al. 2013).

Convertido con el tiempo en imagen emblemática del urbanismo barcelonés, el Plan de Ensanche (fruto de los numerosos estudios topográficos realizados por el propio Cerdà (destinados a asegurar la eficaz reparcelación eficaz de las antiguas propiedades agrarias) iba a caracterizarse por una ordenación vocacionalmente isótropa del territorio, referida a una extensa malla ortogonal de calles paralelas y perpendiculares al mar, formando una cuadrícula de manzanas de 113 x 113 metros, ajustada a la realidad geográfica de la llanura y al patrón sensiblemente ritmado de sus cursos hídricos.

La movilidad y la fluidez del tráfico iban a ser, de hecho, dos componentes esenciales del $\mathrm{Pla}$ Cerdà.

Además de la innovación de los chaflanes, como aperturas visuales en las esquinas, la mayoría de las calles eran amplias vías de entre 20 y $30 \mathrm{~m}$ de anchura (combinadas con avenidas de 50 a $80 \mathrm{~m}$ de ancho) diseñadas para facilitar la comunicación rodada y la conexión entre el puerto y las dos salidas geográficas de la ciudad, hacia el valle del Llobregat y el valle del Besós (por el Paralelo, la Meridiana y la Gran Vía como conexión transversal entre ambas).

Más que un trazado con voluntad compositiva, el Plan se proponía como un sistema operativo -preciso, riguroso y adaptable en el tiempo- que permitía extenderse sobre la virtual "tabula rasa" de la llanura agrícola, adaptándose a sus accidentes y preexistencias.

Aunque interpretado como paradigma de la homogeneidad urbana, el Pla Cerdà presentaba, ya desde sus orígenes, elementos de variación y distorsión, más allá de la aparente y estricta "retícula homogénea"; no sólo en la disposición y permutación variable de la edificación (destinados a generar grandes espacios verdes en el centro de las manzanas) sino sobre todo en el propio trazado viario, con la aparición inesperada de grandes arterias dispuestas según diversas direcciones, oblícua y/o estratégicamente destinadas a conectar la ciudad a "gran escala" (Diagonal, Gran Vía, Paralelo, Meridiana) o mediante la incorporación de los viejos caminos extramuros (paseo de Gracia, avenida de Sarrià, avenida de Roma, avenida de Ribes, calle de Pere IV, etc.).

Mientras, el desarrollo y auge de la industria textil y metalúrgica catalana (y la aparición de las primeras grandes compañías eléctricas y financieras) iban a afianzar la prosperidad de una burguesía con una clara vocación emprendedora, innovadora y conservadora al mismo tiempo, la progresiva urbanización del Ensanche iba a verse acompañada de un acelerado proceso de reparcelación, debido a las facilidades geométricas y económicas del propio Plan (Busquets 2006; Solà-Morales 2010).

Una nueva versión genuinamente barcelonesa de la casa de alquiler (presente simultáneamente en muchas de las nuevas metrópolis europeas y destinada a asegurar a sus propietarios múltiples beneficios y rentabilidad) se iba a afianzar en el Ensanche, favoreciendo el desarrollo de una nueva estética residencial Modernista, con un gran despliegue creativo y una gran variedad iconográfica, en los casos más destacados o con más contención en las soluciones resueltas por mestres d'obres, pero con la generalizada aplicación de motivos y elementos surgidos de la nueva eclosión de los oficios artesanales autóctonos, favorecidos por las nue- 
vas tecnologías mecánicas (mosaico, vidriería, mobiliario, esmalte, marquetería, esgrafiados).

Un Modernisme que, a pesar de su parentesco con otros movimientos europeos similares surgidos en el resto de Europa a finales del XIX (Arts and Crafts, Art Nouveau, Jugendstil), poseería, en el caso de la arquitectura catalana, sus propias características, al combinarse un deseo de cosmopolitismo cultural con el reencuentro de unos valores identitarios y de una conciencia nacional cada vez más extendida.

La mayor parte de la arquitectura característica del Ensanche se construye a lo largo de las décadas entre siglos, en un proceso dilatado que va a acabar favoreciendo la densificación de la edificabilidad inicialmente prevista, al incentivarse la solución de la manzana cerrada frente a lo que había sido uno de los principales objetivos de Cerdà: la manzana abierta o semi-abierta. Ésta iba a ser una de las primeras grandes paradojas del ensanche de Barcelona: la avidez especulativa de los propietarios convierte lo que era una sistema abierto, bien orientado, dinámico y combinatorio (con generosos espacios ajardinados) en un trazado estático de densas manzanas compactas (Busquets 2006; Solà-Morales 2010; Gausa et al. 2013).

El Pla Cerdà había intentado, por otro lado, evitar cualquier posible jerarquía (a priori) en el espacio urbano. La propia red pretendía evitar la aparición de zonas más privilegiadas que otras.

Las propuestas de las clases preminentes pasaban, por el contrario, por favorecer un ensanche claramente jerarquizado a partir del gran eje central del Paseo de Gracia, una avenida utilizada desde hacía tiempo por la burguesía como espacio privilegiado de ocio y ostentación y que era, de hecho, una extensión virtual de las
Ramblas hacia la Villa de Gracia y la Montaña. La intención era, en efecto, la de establecer claras diferencias sectoriales y “divisiones”, más o menos explícitas, afín de "determinar", desde el principio, la posición de los inmuebles más preciados e impulsar, con referencias claras, el negocio del suelo (Aibar 1995).

Para ello era necesario saber dónde iba a alojarse la burguesía más pudiente y aquella otra con menos posibilidades, las clases medias y las trabajadoras, así como la localización de las construcciones fabriles y los equipamientos y servicios asociados.

El Pla Cerdà no ofrecía una respuesta explícita a dichas cuestiones, pronto la zona alrededor del Paseo de Gracia iba a ser considerada como el espacio residencial más privilegiado para la aristocracia y la alta burguesía. Los precios de la tierra y de los bienes inmuebles se iban a establecer, así, en función de su proximidad al binomio Paseo de Gracia / Rambla Catalunya (una nueva vía que enlazaba tanto en su trazado como en su tipología, en salón central, con la propia Rambla tradicional, conjugándose con el modelo del "boulevard" parisino, típico del Paseo de Gracia).

Esa doble púa recogía y "continuaba" ahora el antiguo eje central de la ciudad histórica pero también muchas de sus inercias. Ya desde las primeras décadas de su desarrollo la parte central y derecha del ensanche iban a alcanzar un mayor nivel de calidad y prestigio que la parte izquierda. Vivir en la parte central o en el "lado derecho" del ensanche iba a ser durante mucho tiempo un signo inequívoco de distinción social en Barcelona (Aibar 1995). Esa alteración constituía una importante desviación del propio plan, al establecerse una clara división jerárquica entre un espacio "central/axial”, 
un "lado derecho" y un "lado izquierdo" en el propio ensanche. Una diferenciación que era, en efecto, el reflejo de una asimetría más lejana entre las dos mitades de la propia ciudad antigua. Sólo que ahora el eje central de la Rambla se había "ensanchado" en un cuadrado virtual... y "virtuoso".

La transferencia de esta división indicaba como el ensanche se estaba desarrollando como una extensión de la propia ciudad antigua, con la implícita consolidación de una parte "central" que aparecería, así, como una prolongación virtual de los ejes verticales y laterales del antiguo pentágono de la Ciutat Vella (Sant Antoni/Aribau a la izquierda y Ciutadella/Sant Joan a la derecha) y que poseería, en ese doble eje central definido por el Paseo de Gracia y la Rambla de Catalunya, sus claros referentes.

A lado y lado de este "Cuadrado de Oro" se extenderían, a la derecha, un Ensanche todavía prestigiado (marcado por la presencia del nuevo Parque de la Ciutadella y de las estaciones de tren del Nord y de Francia, etc.) y, a su izquierda (de nuevo) una zona más ligada a los servicios y a los grandes equipamientos urbanos como los mercados de Sant Antoni, la Universidad, el Hospital Clínico, la Escuela Industrial, el Hospital de la Maternitat, la Cárcel Modelo, etc. y destinada a una clase-media burguesa menos pudiente,

De hecho, a pesar de la isotropía preconizada desde siempre por Cerdà, esa lateralización hacia la derecha, consciente o inconsciente, aparecía ya desde el inicio en el proyecto, donde la Plaza de la Glorias (cruce simbólico, ilustrado, de la Diagonal con la Meridiana) junto a la Plaza Tetuán (en el importante cruce de Gran Vía con Paseo Sant Joan) debían constituir nue- vos polos atractores frente al viejo casco histórico: centralidades nunca bien resueltas ni bien diseñadas del todo.

La reforma del casco antiguo constituía, en cualquier caso, otra importante apuesta del Plan: tres avenidas, A, B, C-dos perpendiculares y una transversal- debían penetrar a través del tejido irregular del casco viejo (como prolongaciones de otras tantas avenidas del ensanche) para dar continuidad transversal al mismo, sobre todo en el sentido Montaña-Mar y su relación con el puerto. Sin embargo, de las tres vías previstas tan sólo la A, la Vía Layetana (desarrollada en el "lado derecho" del casco histórico, enlazado con el Paseo de Gracia y Pau Claris) iba a acabar realizándose por completo; la vía horizontal (C) sólo se iba a abrir en un pequeño tramo, generando una mínima dilatación en el espacio urbano y frente a la Catedral. La segunda de las vías verticales (B), situada a la izquierda, aunque debía conectar dos puntos nodales (la plaza de la Universitat y la calle Muntaner con la parte posterior de las Atarazanas), no iba jamás a verse realizada e iba acabar convertida, en lo años 80 , en un remedo paradójico de Piazza Navona y Rambla Interior rodeada por edificios de calidad anodina (Rambla del Raval).

El rápido crecimiento urbano en el Ensanche iba a obligar, en cualquier caso, a resolver el encuentro con los pequeñas villas y municipios circundantes (Plan Jaussely 1905; Plan de Enlaces 1917) un problema que apenas había sido apuntado por el propio Cerdà, más allá del ajuste de la propia malla a los diversos episodios con los que se iba encontrando. La progresiva agregación de poblaciones como Sants, Les Corts, Sarrià, Sant Gervasi, Gràcia, Horta o Sant Andreu que (desarrollados en un 
arco discontinuo situado entre el antiguo borde del No Man's Land militar y las estribaciones del Tibidabo) iba a ser paralela a la acelerada densificación del Ensanche y a la progresiva extensión de la red de transportes públicos hacia la propia montaña. Ambos procesos iban a favorecer el desarrollo de otro tipo de modelo urbano "alternativo" localizado en las grandes fincas colindantes junto a los núcleos agregados. Los modelos anglosajones de la ciudad jardín, iban a verse reflejados así, con diversas variantes, tanto en los programas para grandes equipamientos (nuevos colleges religiosos, conjuntos hospitalarios con pabellones aislados, grandes edificios hoteleros o administrativos) como en las diversas operaciones de urbanización basadas en viviendas unifamiliares, para residencia y/o recreo ("torres") tan características de la Bonanova, Sant Gervasi o la villa de Horta. Entre dichas operaciones, el parque Güell y la urbanización de la Avenida del Tibidabo, promovidas respectivamente por el conde de Güell y el Doctor Andreu, constituirían dos de los exponentes más claros de la vocación de una cierta burguesía, más elitista y aristocrática, por alejarse de la compacidad edilicia y economicista del nuevo centro urbano -y de su modelo tipológico de casa rentabilizada, en continuidad y contigüidad- hacia una nueva "parte alta" más medioambientalmente cualitativa y que empezaba a significarse como una nueva localización de élite (más elevada y más distanciada, a todos los niveles). Las antiguas divisiones socio-urbanas entre "izquierda, centro y derecha" se combinaban ahora con otras, entre escenarios "altos, medios y bajos".

Durante las dos primeras décadas del siglo XX y coincidiendo con la favorecedora situación económica (y la posterior neutralidad durante la Gran Guerra) Barcelona y Cataluña iban a acabar convirtiéndose junto al País Vasco en los principales centros industriales de España, atrayendo asimismo la inversión de numerosas empresas extranjeras con sede y delegaciones en la ciudad (Maluquer 1994).

Equipamientos e infraestructuras acordes con una nueva vocación cosmopolita (estaciones ferroviarias, hoteles, teatros y grandes almacenes), así como nuevos espacios representativos (como la plaza de Catalunya, gran rótula urbana entre la ciudad histórica y la nueva ciudad) iban a definir, así, un nuevo paisaje urbano decididamente más metropolitano materializado en la primera línea de metro, inaugurada en 1924 (entre las plazas de Catalunya y Lesseps) o en la emergencia de nuevos escenarios urbanos como el Paral.lel, eje bohemio de la ciudad (teatros Apolo, Arnau, Molino, etc.) y foco de un asociacionismo obrero, particularmente activo y presente tanto en el Poble Sec como en el Poble $\mathrm{Nou}$, un nuevo barrio nacido en las grandes extensiones litorales próximas al antiguo núcleo de Sant Martí de Provençals, en la parte baja del Besós (Prieto 2017).

La abundancia de agua y el bajo precio de los terrenos habían favorecido, ya desde el siglo XVIII, la instalación de diversas manufacturas y talleres a vapor y la aparición posterior de almacenes y fábricas de creciente importancia. Dichas preexistencias eran ya notorias durante la elaboración y aprobación del Pla Cerdà: la aplicación del propio Plan en esta zona iba a acabar aceptando esa realidad fuertemente industrial, logística y trabajadora, con un tipo de adaptación de las manzanas planteadas, preferentemente, como módulos fabriles y/o de almacenaje (y eventualmente residenciales) y la conversión de las calles en grandes viales de 
transporte y maniobra. En la evolución del propio Ensanche se propiciaba, pues, otra división, no siempre explícita ni bien narrada (pero fundamental) entre la nueva ciudad reticular central -por encima de la nueva Gran Vía (el gran eje horizontal y transversal de la ciudad, junto a la calle Aragón) - y la vieja ciudad histórica con el sector del Ensanche situado por debajo de dicho eje y que iba a acabar alojando la mayor parte de las fábricas e instalaciones manufactureras y obreras en un territorio que pronto iba a alojar la mayor concentración industrial de España (el denominado Manchester catalán) con un crecimiento demográfico creciente y la consiguiente auto-construcción de barracas y chabolas en las playas del Somorrostro, Pequín, Bogatell, etc.

La Gran Vía (la gran flecha de doble conexión N/S) dividía pues, de nuevo, la ciudad entre la nueva zona "central" y la zona "litoral" (más baja) con un carácter cada vez más popular y laboral tanto en el casco antiguo como en el Poble Nou, destinados a alojar aquellas capas sociales con menores capacidades adquisitivas.

En cualquier caso, los rápidos progresos mecánicos, la incorporación de las nuevas tecnologías en Catalunya y el desarrollo gradual de la electrificación (con el importante aprovechamiento de los recursos hidráulicos y térmicos en un territorio no del todo autosuficiente) iba a favorecer un importante aumento de la productividad económica, complementando el auge de la industria textil con la aparición de nuevos sectores como el químico, el farmacéutico, el automovilístico y el metalúrgico, las industrias constructivas y decorativas, la impresión de calidad, la edición, o la alimentación, etc. (Maluquer 1994; Pascual 1999).
La sustitución barcelonesa del ideario simbólico e identitario "nacional-romántico" por una nueva conciencia cosmopolita de "City" con vocación internacional (Chicago o Londres como nuevos paradigmas) coincide con el desarrollo de una ciudad ya claramente industrializada (y con un importante crecimiento) preocupada por convertir en valores ideológicos los procesos materiales -más que líricos-y su propio crecimiento.

El lenguaje local/universal de una nueva cultura Noucentista, orientada hacia los valores ponderados de una recuperada tradición clásica mediterránea, favorece una posible concertación entre vocación universal y producción "próxima", vinculada a un proyecto de recuperación del espacio urbano como lugar de una civitas mediterránea atemporal, cuidada -y guiada- a través de un orden y progreso de claros valores "( $t$ ra(di)cionales". En este contexto, la Exposición del 29, concretada en plena dictadura de Primo de Ribera (1923) y focalizada en el diseño ajardinado de la montaña de Montjuic y la urbanización de la Plaza de España, permite evidenciar los importantes avances (electrificación, tecnificación, etc.) de una ciudad vocacional -y ponderadamente- "moderna", con la importancia de diversos pabellones de prestigio entre los que iba a destacar el Pabellón de Alemania, como manifestación de una nueva capacidad material y productiva y de un nuevo movimiento (el Moderno) que se expresaba, así, ante a los ojos atónitos de los visitantes nacionales e internacionales. Curiosamente, la presencia del Pabellón de Mies van de Rohe iba a fijar una fecha clave de la vanguardia internacional coincidente, poco después, con el Gran Crack mundial del 1929 -la Gran Depresión- y en 
España con la caída de la dictadura de Primo de Rivera (en 1930) y la posterior caída de la Monarquía (en 1931) que iban a dar paso a una rápida sucesión de acontecimientos históricos como la instauración de la Segunda República española (1931-1939) y la reinstauración de la Generalitat de Catalunya (1931-1934 // 19361939) (Gausa et al. 2013).
El flujo de inmigrantes había seguido creciendo en la ciudad generando una elevada demanda de vivienda traducida, a menudo, en especulación y/o barraquismo. El problema de la vivienda se conformaba, así, como uno de los grandes temas del momento. En octubre de 1930 se había formado el GATCPAC (Grup d'Artistes $i$ Tècnics Catalans per al Progrés de l'Arquitectura

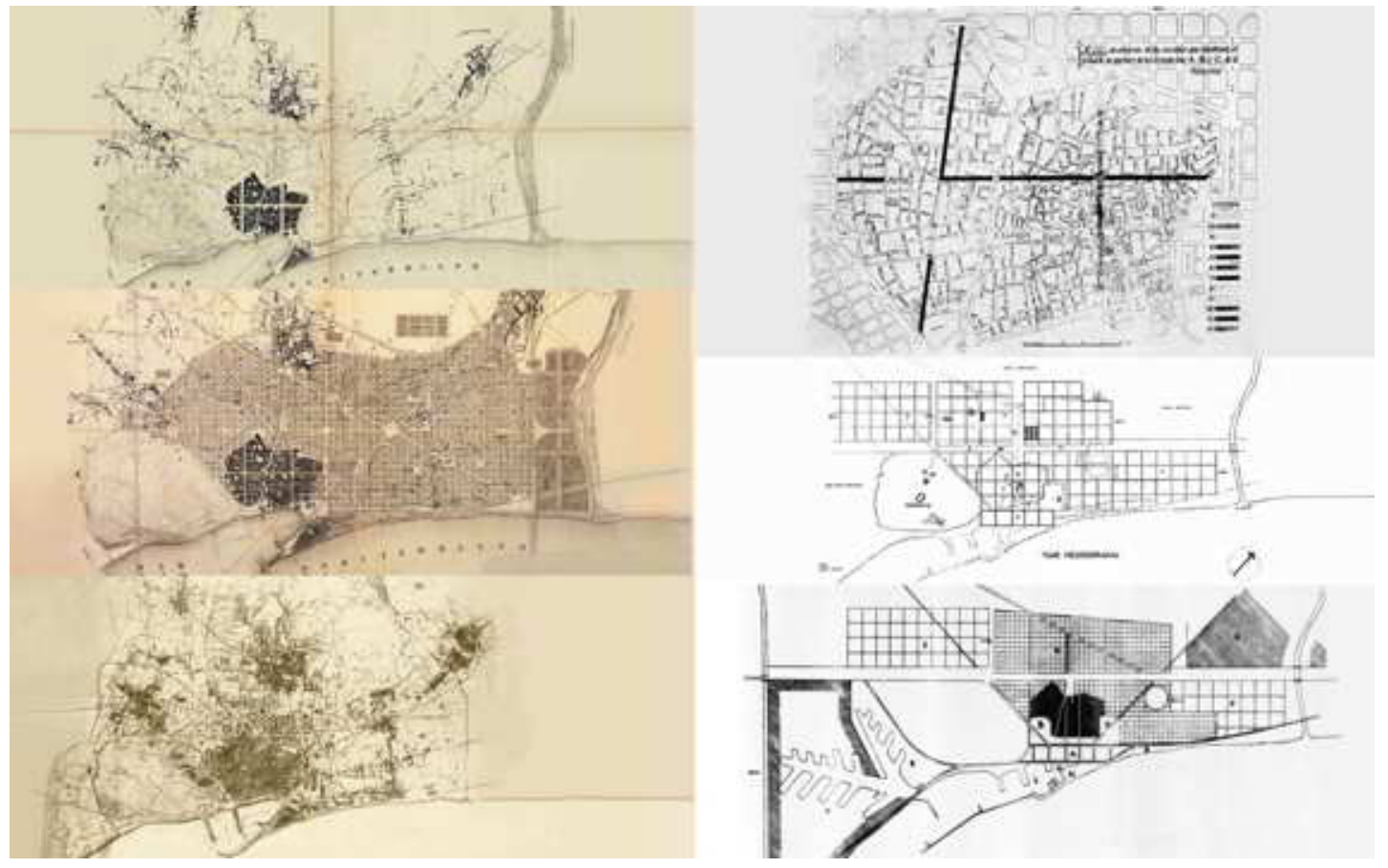

Fig 3. Barcelona: la retícula y el cuadrado central, el arco de las poblaciones agregadas y la flecha de la Gran Vía.

Izquierda, de arriba abajo: Plano de estudios topográfico de los alrededores de la ciudad de Barcelona (en la que se aprecia el Arco de los futuros pueblos agregados y los principales caminos y cursos hídricos (1858) y Plano de reforma y Ensanche de Barcelona de Ildefons Cerdà (1859) / Plano general de Barcelona y su ensanche en construcción y de los pueblos agregados (1890), en el que se puede apreciar la importancia del sector central (como extensión del perímetro de la ciudad antigua) y las diferencias entre Izquierda y Derecha del Ensanche, así como las preexistencias fabriles del Poble Nou (por debajo de una incipiente Gran Vía).

Derecha, de arriba abajo. Grandes vías A, B y C de penetración en el plan de reforma Baixeras (1907) / Plà Macià, 1931. Versión con el esquema abstracto a base de Super-bloques (con la Gran Cruz del Paseo de Gracia / Gran Vía y la disolución de la ciudad histórica y versión definitiva zonal, en el que se recupera la manzana Cerdà y la Ciudad Histórica -en la parte Central- y se localizan dos nuevas áreas en la parte Izquierda e Inferior de la Gran Vía como gran Flecha direccional y divisoria. 
Contemporània), generalizado en toda España bajo las siglas GATEPAC y vinculado a un ideario de progreso republicano, con una óptica racionalista muy próxima a los postulados de Le Corbusier y destacada componente urbana y social. Su importancia iba a consolidarse con el encargo del Pla Maciá (1934), un plano urbano llamado a materializar un proyecto a escala urbana -la Nova Barcelona- para una nueva ciudad funcional, político-administrativa y obrera, abierta a la importante influencia del progreso y de las vanguardias. El Pla Macià, aunque enunciado tan sólo a nivel teórico, iba a anticipar algunas cuestiones urbanas importantes al proponer nuevo módulo edificatorio para la ciudad, configurado por 3x3 manzanas de Cerdà: los llamados super-bloques, recuperados y reinterpretados más recientemente como super-manzanas, desde una nueva óptica asociada a la limitación de la movilidad y la pacificación ecológica y paisajística de numerosas vías como nuevos espacios peatonales (Rueda 2011).

Pero también iba a abandonar la idea del gran cruce propuesto por Cerdà en la Plaza de la Glorias (Diagonal/Meridiana) para reforzar una nueva Super Cruz compuesta por el Paseo de Gracia y la Gran Vía.

Una Gran Vía ensanchada, redelineada y ampliada y que, con su trazado transversal y tangencial al Casco Histórico y a Montjuic, y iba a establecer -y consolidar- la importante división entre el nuevo tramo superior de la ciudad y el tramo inferior -llamado a absorber y "disolver" la ciudad antigua (¿o anticuada?) y a alojar la propia ciudad industrial (próxima al mar) - en una clara zonificación funcional entre espacio residencial central.

Aunque en su versión más conocida la malla aparece completamente regular, isótro- pa y homogénea, la división marcada por la Gran Cruz y la Gran Vía subyace en las diversas versiones donde aparece claramente explicitada esta división, de nuevo, entre parte central (axial) y parte inferior, lateral, no muy diferente de la generada por el propio $\mathrm{Pla}$ Cerdà. De hecho, a pesar de la regularidad racional del trazado, éste acaba aceptando (desde el "realismo pragmático" y desde el "cartesianismo racional") esa taxonomía -tan ligada al eslogan "living-working-resting"- de una planificación funcional/zonal, canónicamente dogmática entonces.

\section{LA COSTRA Y LA DIAGONAL. LA BARCELONA DESARROLLISTA CENTRO VS. PERIFERIA; "DIAGONAL ARRIBA" / "DIAGONAL ABAJO"}

La brusca interrupción de la Guerra Civil (1936-1939) y la nueva situación generada en la inmediata posguerra significan un repentino paréntesis caracterizado por una mayor inclinación hacia valores de carácter áulico y trascendente basados en un cierto academicismo monumental o histórico, combinados con ciertas caligrafías neo-noucentistes, vagamente inspiradas todavía en el eclecticismo neoclásico mediterráneo.

Entre 1936 y 1939, la ciudad había sufrido más de 200 bombardeos con miles de muertos y heridos. La recalificación de las zonas urbanas más deterioradas iba a favorecer una cierta especulación inmobiliaria y la construcción de viviendas levantadas sin una planificación urbanística previa, con un notable aumento de la altura de los edificios (Prieto 2017). 
Sin embargo, después de una década de privaciones y estricta autarquía en la inmediata postguerra, a mediados de los años 50 e inicios de los 60 una ligera corriente de recuperación económica favorecida por un incipiente contacto con el exterior tiende a evidenciarse: la masiva ayuda americana a la Europa aliada de la posguerra mundial -Plan Marshall- amplía a partir de 1950 su campo de operaciones a la España de la dictadura gracias a la instalación de bases americanas de importancia geoestratégica (lo que se combina con la entrada de divisas provenientes en gran parte de la numerosa población emigrante exterior y de un incipiente turismo de sol y playa). La emergencia de una nueva "mirada crítica", concretada en diversos movimientos artísticos y creativos (Grup R, Dau al Set, Escola de Barcelona, etc.) vinculados a una cierta élite intelectual, ilustrada y comprometida) favorece un renovado afán de debate -sintetizado de un modo esquemático-, entre el "realismo" de una arquitectura contenida y "combativa" ante un contexto con graves déficits materiales y sociales y un "idealismo" de vocación tecnológica, menos ideológico y más profesionalista, decidido a colaborar con el desarrollismo del país.

El progresivo crecimiento económico y demográfico de la ciudad y su fuerte actividad urbana conllevan una rápida ocupación de las áreas de suelo edificable, un incremento de los procesos auto-organizados (barraquismo, chabolismo, sub-arrendamiento, etc.) y un fuerte boom constructivo materializado, sobre todo, en una periferia deficitaria y a menudo suburbial, de importantes consecuencias peri-urbanas.

En este sentido, entre finales de los años 50 y los años 60 se construyen en Barcelo- na toda una serie de operaciones residenciales destinadas a alojar esa fuerte migración trabajadora desplazada desde el campo hacia una ciudad, cada vez más hacinada en sus espacios tradicionalmente más humildes.

El Congreso Eucarístico de 1952 obliga a una primera gran operación de realojamiento con la construcción acelerada de las Viviendas del Congreso, en el Guinardó. Le seguirían otras operaciones de gran impacto como las del Polvorí (1954), Montbau (1957-65), La Mina y el Besós (1958-66), Sant Adrià-Milans del Bosch (196264), Sant Cosme (1966), Bellvitge (1966-68), Nou Barris, etc. creándose así una especie de rosario de suburbios en los suelos disponibles de la corona (o mejor de la "costra") periférica de la ciudad. Muchas de dichas operaciones responderían a los propios patrones plásticos y volumétricos de la planificación abstracta moderna (separación entre bloques y posiciones relativas convenientemente orientadas, vacíos intersticiales, combinaciones tipológicas, zonings funcionales, etc.) aunque realizadas de un modo más mecánico, repetitivo y, a menudo, estandarizado, con una construcción deficitaria, una notable carencia de servicios y equipamientos (y espacios públicos de calidad) y una definición mínima de las viviendas. La aparición de esa nueva realidad suburbial o peri-urbana, nacida precisamente en el tradicional perímetro entre ríos de una "nueva" ciudad relativamente reciente (apenas 50 años habían pasado de la consolidación efectiva del Ensanche) iba a marcar una nueva división entre "centro" y "periferia": entre urbe (tradicional, mixta, prolija) y suburbio (para-moderno, monofuncional, deficitario); es decir entre "ciudad equipada" y "ciudad dormitorio"; entre la "costra" dura (abstracta y carencial) y el "núcleo" central, más amable (concreto y relacional). 
En este contexto, el Plan Comarcal de 1953 iba a plantearse como un primer intento de estructuración conceptual del sistema: una lógica elemental de "bolsas" y conjuntos "zonales" en una ciudad cada vez más ampliada hacia el Besós y el Llobregat. Su aprobación no iba a impedir el desenfreno especulador de unas operaciones inmobiliarias que iban a generar un, cada vez mayor, descontento popular (Prieto, 2017).

Las primeras revisiones del Plan Comarcal del 53, realizadas en los términos del Plan Director (1968) o en los del Plan 2000 iban a orientarse a resolver, más bien, la creciente densidad del tráfico y la definición de un modelo de ocupación a escala infraestructural y territorial.

En este sentido, la construcción del Primer Cinturón (en realidad un gran eje transversal destinado a atravesar la parte alta de la ciudad y conectaría con la nueva Zona Franca y el Puerto, por un lado, y con la Meridiana y la salida hacia el Norte, por el otro) trazaba un nuevo eje sinuoso que se significaba, con decidida importancia, en los nuevos cruces y sectores próximos a la Diagonal Norte (Via Augusta, Francesc Macià o los nuevos Campus Universitarios). Las "zonas altas", alrededor del nuevo cinturón, iban a sintetizar de alguna manera, un nuevo escenario urbano y ciudadano con claras fronteras de "clase", en el que a la división tradicional entre un centro urbano (compacto y familiar) y una periferia suburbial y conflictiva (suficientemente acotada en los nuevos polígonos residenciales) se añadiría la materialización de esa gran zona alrededor del tramo Norte de la Diagonal. Una nueva división urbano-social -con una Barcelona de la "Diagonal Arriba" (zona alta) y una Barcelona de "Diagonal Abajo" (zona baja) - surge, así, sin una clara geometría más allá de la generada por los conos generados entre los cruces superiores de la Diagonal y la Vía Augusta o los inferiores de la Diagonal y la Meridiana/Gran Vía, manteniéndose -en cualquier caso- una "zona centro", con el Paseo de Gracia como eje básico hacia la Ciudad Histórica.

Coincidiendo con ese periodo de crecimiento económico, demográfico e inmobiliarias más o menos controlado, buena parte de la nueva clase media-alta pujante se va a desplazar, en efecto, desde el Ensanche hacia esa nueva parte alta de la ciudad. Las aperturas del primer cinturón y las mutaciones consecuentes de los ejes y tramas cruzadas o atravesadas (como las calles Balmes, Ganduxer y Aribau en sus tramos superiores, o las zonas de la Via Augusta y de la Bonanova, situadas en su mayoría en las antiguas villas de Sant Gervasi y Sarrià) asisten a la rápida desaparición -en un lapso de apenas unas décadas- de lo que habían sido grandes mansiones y "torres" señoriales y selectas y su substitución por bloques de viviendas en altura, basados en nuevas tipologías residenciales alejadas, muy a menudo, de la tradicional vivienda profunda con pasillo, típica del Ensanche: bloques de caligrafía más o menos afortunada, con terrazas frontales más que con pequeños balcones, con grandes aperturas más que con estrechos ventanales, con amplias habitaciones y espacios ventilados y nuevas estéticas "funcionalistas" o "estructuralistas", con algunos ejemplos de calidad (y otros menos logrados) que privilegiarían, en cualquier caso, la densificación y la edificación por encima del espacio público y de las amplias áreas verdes. Las preocupaciones de orden lingüístico se iban a combinar, así, con las de orden económico, funcional y técnico, en unas “arquitecturas de síntesis”, profesionalmente eficientes, propias de un nuevo "standing” y vin- 


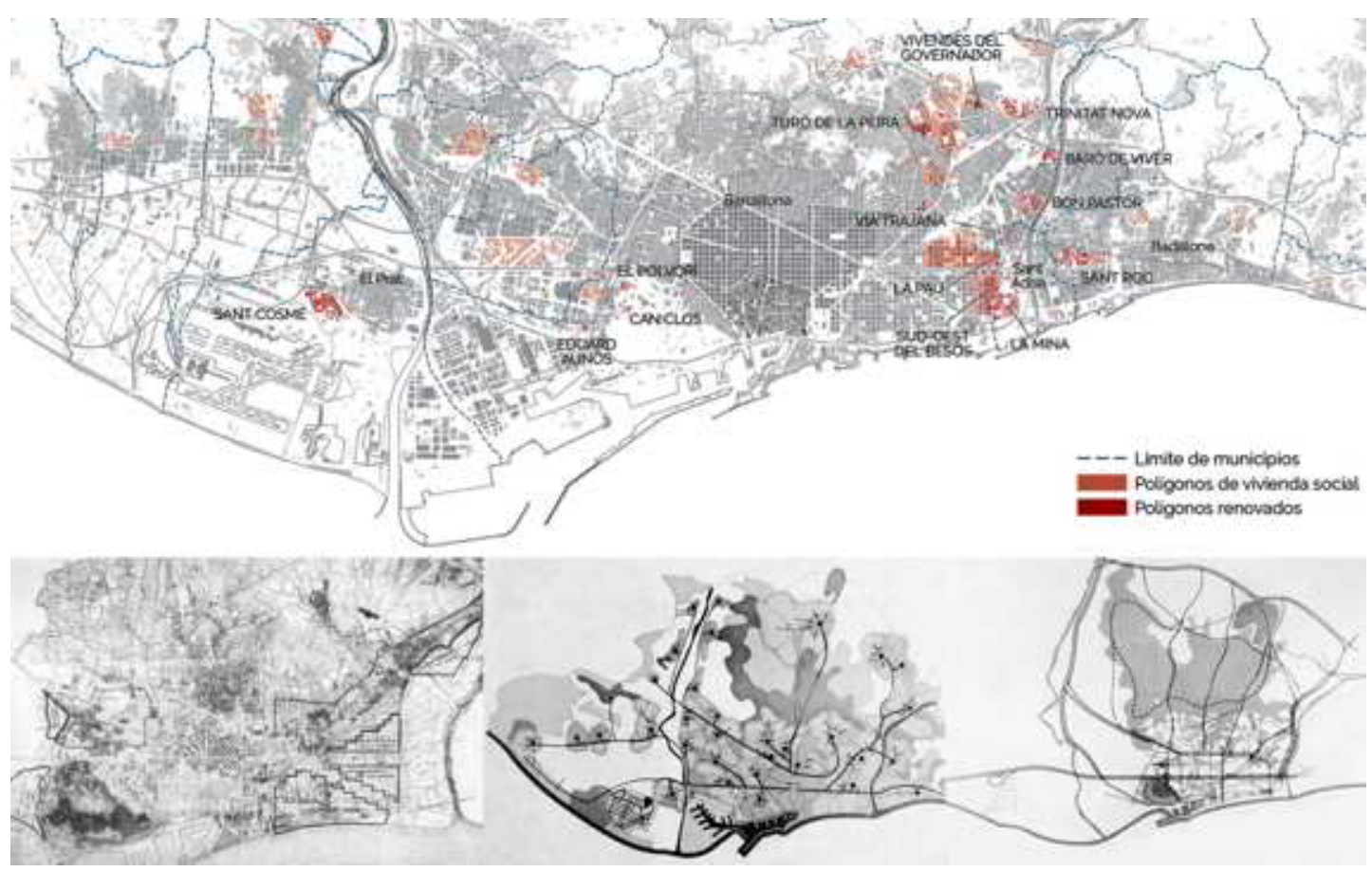

Fig. 4. Barcelona, la "costra" suburbial y el gran corte de la Diagonal.

Arriba: Mapa de Barcelona con la localización de los diversos polígonos de viviendas sociales en la periferia o "costra" de la Barcelona "entre ríos" (Fuente: A. Martínez Gutiérrez, 2017. La renovación de los polígonos de Barcelona.

Barcelona: UPC).

Abajo, de izquierda a derecha. Plano de las principales ubicaciones industriales en 1920 / Plan Soteras de Ordenación General de Barcelona, 1953 y Plan 2000, Subías, Escudero, Riera, 1970, donde se manifiesta la importancia de la construcción de la Diagonal y el Primer Cinturón de Barcelona (Ronda General Mitre).

culadas al nuevo paisaje de las grandes arterias, en el que la idea de ciudad escapa por primera vez al concepto de alineación de vial, con una mayor libertad de desarrollo formal y la presencia característica de "micro-jardines" en los nuevos frentes residenciales de calidad.

En cualquier caso, la exploración del propio lenguaje arquitectónico -cristalizada en años anteriores entorno al debate entre "realismo" e "idealismo" y la revisión del funcionalismo internacional, e implícita en la construcción de esa Zona Alta, alrededor del Primer Cinturón, de los nuevos campus universitarios de la Diagonal Norte e incluso de los propios polígonos residenciales- se ve, en último término, influenciada por la llegada de nuevas referencias surgidas de las tendencias críticas y revisionistas, características de los años 70, favorecidas por la gran "crisis" del 75 y el fin de la idea optimista y desarrollista de un progreso moderno y universal. El inicio de una "postmodernidad" ecléctica y pragmática iba a coincidir, en nuestro país, con la nueva asunción de la democracia, llamada a recuperar una función más 
social, colectiva e intencional del planeamiento urbanístico (Bohigas 1986; Busquets 2006; Solà-Morales 2010).

\section{EL ANILLO Y LA SIERRA. LA BARCELONA "DEL CAMBIO", PRE-Y POST- OLÍMPICA. \\ RECONSTRUCCIÓN, METÁSTASIS Y SALTO DE ESCALA.}

El cambio político producido en el país a mediados de los setenta y el consecuente compromiso de la administración con una producción pública destinada a paliar los déficits históricos acumulados iba a favorecer, en efecto, la anhelada asunción de un cierto ideal ilustrado: el de la "reconstrucción y armonización del espacio urbano" considerado desde entonces el principal objetivo del urbanismo barcelonés.

Tras las primeras elecciones municipales de 1979 y con el Plan General Metropolitano de 1976 aprobado (un documento redactado en los estertores de la dictadura desde la resistencia política y confiado en la concepción del plan como mecanismo público de control frente a las amenazas especuladoras del momento) en el programa de acción del nuevo urbanismo barcelonés liderado por el nuevo Delegado de Urbanismo, Oriol Bohigas, la figura del "proyecto frente al plan" iba a cobrar un valor de "instrumento clave", en esa deseada política de "regeneración" "cívica" conectada con los propios objetivos de reconstrucción urbana -de continuidad y diálogo con la "forma" de la ciudad tradicional- asociados a las, entonces influyentes, teorías revisionistas de "vuelta atrás" que, en buena parte, habían marcado el ideario intelectual de la última década.
Más que abordar la ciudad desde lógicas globales se trataba de recalificarla desde minuciosas intervenciones de "sutura" y "arredo", susceptibles de propiciar una "metástasis regeneradora" en los tejidos abordados: un "modus operandi" implícito en todo el entramado de intervenciones públicas generadas entonces y entendidas como elementos de integración, cohesión y/o rehabilitación contextual: intervenciones derivadas de una lógica centrada fundamentalmente en las esferas de un elegante diseño filo-, para- e hipo- monumental, de suave y ecléctica tentación figurativa, proclive a la definición de recreadas atmósferas "neo-domésticas". Un mapa de las actuaciones desarrolladas en Barcelona durante la primera mitad de los ochenta mostraría, en efecto, el encaje pragmático y puntillista de un profuso repertorio de intervenciones dispersas sobre una cartografía ajustada a los límites tradicionales de la ciudad. El intento de estructuración de ese gran punteado intersticial mediante su agrupación en posibles "lógicas de conjunto" zonas coherentes y más o menos envolventes, las Áreas de Nueva Centralidad concebidas por Joan Busquets- iba a constituir un notable esfuerzo sistemático evidenciando, sin embargo, la persistencia de una lógica operativa confiada todavía en la suma virtuosa de unas actuaciones ahora más estratégicamente localizadas (Bohigas 1986; Busquets 2006).

La entrada de España en la Comunidad Europea en 1985 y la posterior y decisiva "Operación Olímpica” -la gran culminación en 1992 de todo ese proceso- iba a acabar evidenciando no sólo los logros sino los límites de dichas dinámicas y la necesidad de establecer otro tipo de estrategias más allá de las pequeñas intervenciones episódicas, de sutura y coyuntura. 
La disposición estratégica de las propias Áreas Olímpicas entorno a las nuevas Rondas, iba a significar, de hecho, uno de los factores más decisivos del reciente urbanismo barcelonés: la materialización no sólo de un nuevo tipo de "espacialidad" anular sino, también, de un nuevo tipo de "topología" urbana relacionadas con la movilidad y la urbanidad al mismo tiempo: una nueva escala favorecida por el desarrollo económico e infraestructural de los años 90.

La confianza en una eficiente "gestión urbana" (personalizada, entonces, en la figura coordinadora de José Antonio Acebillo) iba a verse potenciado en los posteriores corolarios urbanos, "post-juegos": una compleja etapa de resaca económica y búsqueda de una rápida amortización de los activos conseguidos, apoyada principalmente en el relanzamiento inmobiliario y terciario, el nuevo papel turístico de la ciudad y la consolidación de su propia "marca" de calidad: la apertura del tramo Sur de la Diagonal y su acelerada formalización, la recuperación y reestructuración del Besós, las remodelaciones de Ciutat Vella y del Port Vell y la construcción de las nuevas zonas e instalaciones urbanas vinculadas al desafortunado "Forum 2004" o la redefinición de nuevos "paquetes de desarrollo mixto", notablemente en la Sagrera, la Zona Franca o la Plaza Europa y su articulación con 1'Hospitalet, así como en el relanzamiento del Poble Nou (con la nueva clasificación urbana, el 22@, destinada a favorecer suelos de usos mixto, apenas explotada en todos sus potenciales) constituían oportunidades que hablarían de una ciudad localizada definitivamente en el mapa urbano internacional y que abogaría, ahora, por un nuevo papel en el mercado global, no exento de tentaciones economicistas y de seducciones iconográficas.
Tentaciones que, si bien habrían superado la tradicional y excesiva "auto-referencia" productiva y disciplinar de los años ochenta, habían visto emerger, casi de repente, un nuevo tipo de tendencia hacia la "para-arquitectura" estándar, el "marketing urbano", el "formulismo snob" o el coleccionismo glamouroso y vedettista de objetos y firmas singulares. Una tendencia apoyada en la iconografía más que en la ideología y progresivamente inclinada hacia las listas de "mérito" y las piezas de diseño (convencionales y/o convencionadas, por "convenientemente convenidas") o hacia la paradójica "estandarización de lo excepcional”, es decir, hacia la universal comunión, aquí y allá, de "franquicias" y "marcas" con resultados "garantizados".

En cualquier caso, en una nueva situación "geopolítica" de territorios y ciudades "en red" (sujetos a constantes ajustes y reajustes entre antiguos y nuevos, ejes financieros, culturales o logísticos y referidos, a su vez, a nuevos parámetros de conectividad, eficacia y velocidad) la "marca" Barcelona se enfrentaba, casi de repente, a nuevos retos de investigación, identificación y significación, más allá de los modos, de las formas y de los escenarios ritualmente ensayados. Retos asociados a un nuevo entorno "relacional" e "informacional", abierto a nuevos y complejos procesos de interacción entre campos dinámicos -y múltiples- de fuerzas e (inter)cambios.

Las críticas hacia el excesivo ensimismamiento formal (certificado alrededor de las "buenas prácticas" de la Marca -o Escuela- de Barcelona) no impedirían reconocer como, en la etapa que se extendería desde mediados de los 80 hasta la primera década del siglo XXI, Barcelona iba a experimentar una política equilibradora dirigida a cualificar con similar atención 
los diferentes ámbitos de la ciudad ("recuperar en centro, monumentalizar la periferia", sería uno de los slogans del momento); propiciando un conjunto plural y diversificado, pero homogéneo en la atención a los diversos episodios urbanos abordados (Busquets 2006; Solà-Morales 2008, 2010).

Izquierda, centro, derecha, arriba y abajo, parecían experimentar un nuevo tipo de atención desde la que combinar esa "acupuntura" urbana que tanto publicitaría después. Jaime Lerner en Latinoamérica.

El empeño por evitar, justamente, una ciudad "dividida" desde operaciones de recosido, reconstrucción, re-cohesión, o regeneración (destinadas a "limar asperezas", a "unir", "fusionar" o "disolver" fronteras, fisuras o vacíos socio-espaciales) buscaba ese "acabar la ciudad" preconizado en su momento por Pasqual Maragall.

Con el trazado de las Rondas de Barcelona, destinado a engranar las cuatro Áreas Olímpicas, la ciudad parecía cerrar el círculo: un círculo que la rodeaba, en ese anillo perimetral que convertía toda la ciudad en un gran centro diverso e interno a la vez. No obstante, ese enunciado optimista de una gran ciudad "nudo/nodo", rodeada y acordada a su propia topografía urbana (cada vez más homogéneamente "acabada" en su interior y "articulada" hacia el exterior) sería el que iba a centrar muchos de los importantes debates impulsados por el grupo Metápolis en el traspaso de siglo (19982006) y que, frente a una visión demasiado auto-referencial, convocaba la importancia de las nuevas escalas y procesos urbano-territoriales, ya en curso.

A finales del siglo XX Barcelona se manifestaba, como la mayoría de grandes metrópolis finiseculares, como un sistema en acelerada mutación; un escenario "global" generado "desde", "por" y "entre" variados escenarios "locales". Un escenario que, desde su precisa geometría inicial, había ampliado sus nuevos márgenes más allá de los viejos límites: una ciudad expandida y, sin embargo, "cortada" por su gran Sierra Central. Barcelona ya no era aquella "ciudad entre dos ríos" sino un organismo vital extendido en los grandes corredores del Vallès, detrás de Collserola. Sin embargo, a diferencia de otras metrópolis más llanas como Londres, Paris, Berlín, Madrid, Milán, etc. el tradicional esquema en mancha de tinta radio-céntrica se veía aquí interrumpido por las grandes líneas del mar y de la Sierra de Collserola, la gran cordillera del litoral, una barrera (una división de nuevo) que impedía abarcar toda la escala metropolitana y acababa ensimismando Barcelona en sus límites administrativos y neofigurativos. La ausencia de una reflexión y concepción a gran escala, la escasa entidad decisoria de la propia “Área Metropolitana”, su superación por un nuevo tipo de escenarios con límites y fronteras más elásticos, así como la propia autonomía urbanística de núcleos y municipios había dado como resultado ese sprawl a la catalana, en una peri-urbanidad extendida hacia el Vallès -y el Maresme- y crecida al ritmo de la propia burbuja económica e inmobiliaria de inicios del siglo XX, sin un claro esquema direccional, más allá del antiguo Plan General del 74 (Solà Morales I. 2002; Gausa 2009; Muñoz 2016).

El gran corte de la Sierra de Collserola dividía, pues, la nueva Gran Barcelona dispersa y fractal de la Barcelona tradicional, densa, compacta y continua, ahora circunvalada por el gran anillo de las Rondas. Barcelona, como la mayoría de las grandes ciudades contem- 
poráneas, se materializaba desparramada a gran escala, como un conjunto cada vez más poliédrico y poli-céntrico que, de modo similar al de cualquier sistema complejo desarrollado bajo la influencia de procesos y movimientos diversos, acababa manifestándose como el resultado "para-planificado" de sucesivos acontecimientos con -y sin- voluntad de planificación (Harvey 1985; Gausa 2009; Rueda 2011). El abordaje cualitativo (y no especulativo) de ese nuevo organismo complejo así contemplado, (plural, irregular, heterogéneo y simultáneo, pero rico en situaciones múltiples y diversas) evidenciaba la necesidad de proyectar con decisión una mayor conjugación estratégica entre sistemas y subsistemas (a diversas escalas) favoreciendo marcos de (inter) acción (y de relación) capaces de generar no sólo nuevos planteamientos espaciales y económicos más (co)responsables sino auténticos dispositivos de relación entre informaciones, condiciones, solicitaciones, situaciones y posibles operaciones (Gausa 2009).

Barcelona debía asumir esa necesidad de coordinación urbano-territorial, favoreciendo, en efecto, nuevas planteamientos y marcos de acción capaces de articular un desarrollo sostenible destinado a entrelazar, a través de nuevos esquemas flexibles y vectorizados, mallas de lugares y entre-lugares, de densidades y disdensidades, de paisajes operativos y de paisajes relacionales, de tramas y de circuitos, asociados a una nueva interpretación de lo ecológico (una ecología activa más que nostálgica) capaz de potenciar una idea instrumental del paisaje ya no como un vacío o residuo intersticial sino como un "(sub)sistema operativo" y estructural, abierto al uso, la programación y la actividad (Gausa 2009; Llop 2011).
De un territorio "extraurbano" se trataba de pasar a un territorio "inter-urbano". De un territorio "fondo" a un territorio "malla". De un territorio pasivo a un territorio activo, capaz de equilibrar áreas densas y áreas dilatadas: sístoles urbanas y diástoles multi- e inter- urbanas, capaces generar plusvalías y al mismo tiempo de conservar espacios de reserva. Concibiendo la ciudad "hacia afuera y hacia dentro"; impulsando operaciones de "enlace" pero, también, operaciones de "refuerzo": de consolidación, de contención o de "coagulación", de reestructuración y/o de reciclaje. Frente a las dinámicas mecanicistas de la ciudad difusa pero también frente al paradigma de la gran ciudad compacta y homogeneizadora, una tercera vía defendería así (ya a inicios del 2000) esa nueva definición trenzada o entrelazada, definitivamente "polifónica y polinuclear" (mallada y conjugada, a la vez) de una nueva "multi-ciudad" territorial (Nel.lo 2000; Gausa 2009; Pradel 2016).

Ese salto de la ciudad en y "hacia el exterior" debía combinarse, a su vez, con un movimiento complementario "hacia el interior" acordado al aprovechamiento de los recursos y los tejidos existentes, propiciando operaciones internas de reactivación y redefinición, n-dimensionales. Operaciones capaces de articular una necesaria mixicidad sectorial -y seccional- desde los que plantear nuevos marcos de interacción entre antiguas categorías duales (residencia-industria, público-privado, horizontal-vertical, arquitectura-paisaje, etc.) en nuevos escenarios más complejos e híbridos, concebidos más allá de la vieja planificación zonal (Rueda 2011; Gausa 2017).

Reconexión transversal (y movilidad combinada, rápida y lenta, inter-nodal y pacificada), Reciclaje y mixicidad urba- 


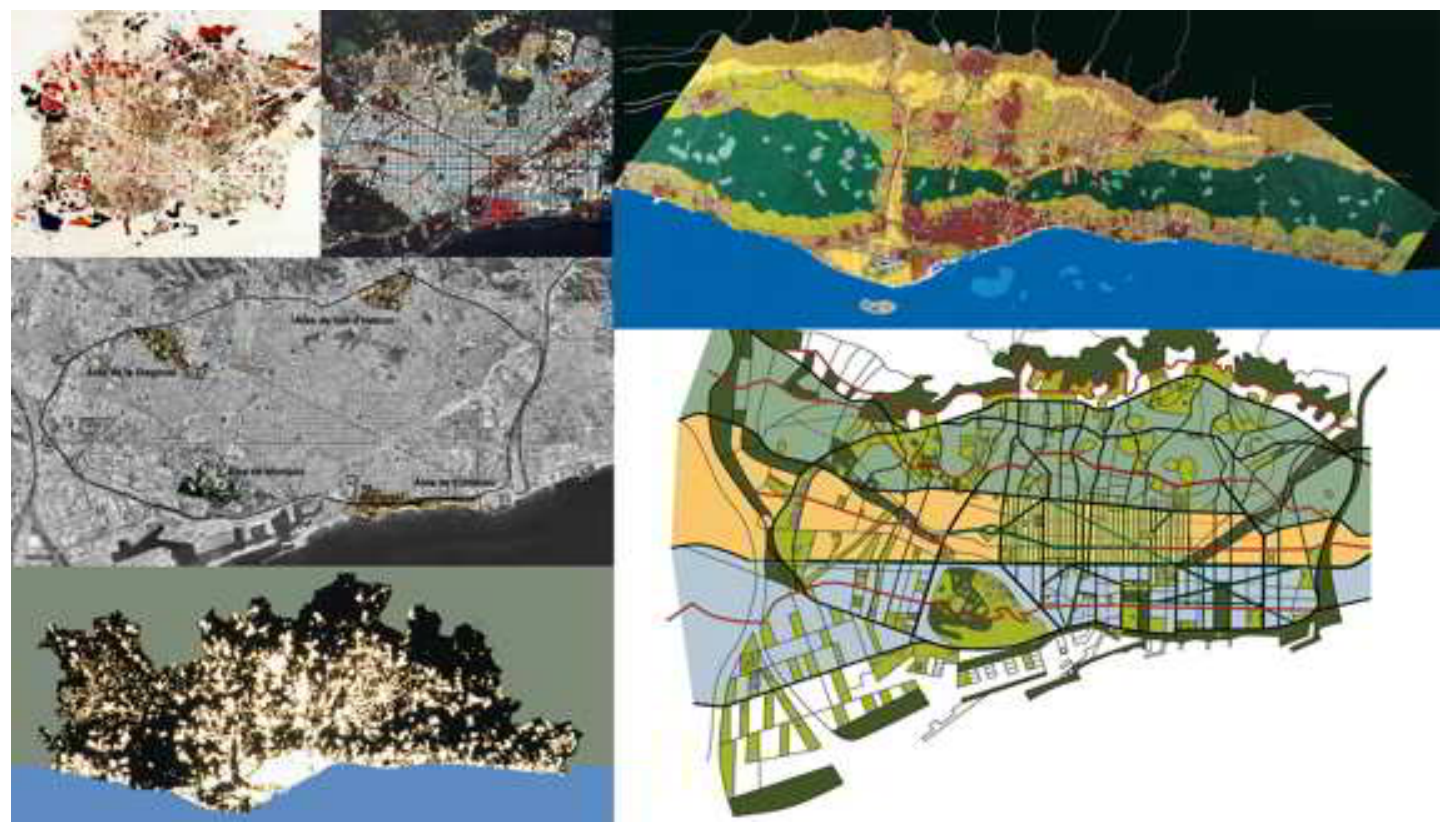

Fig. 5. Barcelona, el anillo de las Rondas y la Sierra de Collserola, como relieve entre corredores de desarrollo.

Izquierda, de arriba abajo. Mapa de Equipamientos (1985-1994) y Áreas de Nueva Centralidad (1987) / Trazado del Anillo de les Rondes y localización de las 4 áreas olímpicas (archivo) / Barcelona, procesos de ocupación de suelo (A Serratosa, en O.P. n. 35, 1996) con la gran Sierra Central como división entre la ciudad compacta central y la ciudad sprawl fractal // Derecha, de arriba abajo. Barcelona Land-Grid, esquema de orientación territorial / Barcelona (en) Bandas y Capas. Proyección de las bandas ámbitos territoriales a nivel de redefinición central: Montaña, Centro, Mar, éstos últimos permutados en uno y otro esquema (Actar Arquitectura, 1998-2001/2008-2010)

nos, Re-naturalización y esponjamiento central, Reconquista de un nuevo tipo de espacio público activo y performativo, Relacionabilidad e interacción colectivas, Re-programación mixtay Reactividad informacional, configurarían los 7 factores Re (de Re-información urbana) que desde una visión holística intentaría reinvertir los propios sistemas de crecimiento $y$ producción hacia estrategias circulares, urbanas e interurbanas, que apelarían a relaciones metabólicas más racionales con el entorno, planteando positivamente el (re)aprovechamiento -el reciclaje y el re-uso, pero también la rearticulacióno la reformulación-de los recursos (Braungarts y Mac Donough 2003; Rifkin 2014; Muñoz 2016; Ricci 2012).

De repente, en un juego de espejos imaginarios, la Barcelona "anular" y la Barcelona "cortada" -la Barcelona del anillo y la Barcelona de la Sierrase reflejarían y reconocerían al mismo tiempo en un patrón similar de esquemas resonantes en los que las franjas de la Barcelona Mar, la Barcelona Centro y la Barcelona Montaña se proyectarían recursivamente -a otra escala- en las grandes bandas de una Barcelona Costa, estirada 
desde el Maresme hasta la Costa Dorada , una Barcelona Cordillera, con Collserola como gran reserva metropolitana, y una Barcelona Ensanchada, en el gran corredor del Vallès (aunque en estos dos últimos casos "Ensanche" y "Montaña” habrían permutado sus posiciones). En cualquier caso, ya no se trataba de hablar de una Barcelona Alta, Media o Baja o de una Barcelona Derecha, Izquierda o Centro, sino de una Barcelona en red(es), diversificada e interconectada. Un lugar de lugares (y entre-lugares) a valorar, entrelazar y potenciar.

Si en las últimas décadas del s. XX la ciudad postmoderna había desarrollado toda una serie de modelos basados en la reconstrucción formal (revisionista), el arreglo compositivo (esteticista), la gestión eficaz (tecnicista) y el marketing comercial (economicista) y apoyados habitualmente en el diseño formal y el oportuno catálogo de marcas garantizadas, glamour vedettista, fascinación terciaria y coleccionismo de importación -ahora ya no se trataba tan sólo de reconstruir, de diseñar o de gestionar la ciudad... sino de "re-informarla" desde una nueva interacción positiva e innovadora (tecnológica, social y creativa) con el medio y entre medios. Con el entorno y entre entornos (Gausa 2009, 2021; Ricci 2012).

\section{7- LAS REDES: MULTI-CIUDADES Y GEO-URBANIDADES. COSTA Y CONTRA-COSTA, UN TERRITORIO ESCORADO: ¿BCN. CAT., HACIA UNA NUEVA CONFEDERACIÓN NACIONAL METROPOLITANA?}

En las nuevas lógicas de la complejidad derivadas del universo digital, después de los aborda- jes pioneros de los años 90 (múltiples, mixtos, híbridos, a-tipológicos), la primera década del siglo XXI iba a caracterizarse por las aportaciones de un nuevo aparato tecnológico vinculado a la eclosión definitiva -a inicios del s.XXI- de Internet, llamado a multiplicar los protocolos de acceso y conectividad y a multiplicar las capacidades de interacción e interconexión entre medios y medio, ciudad y ciudadanos gracias, asimismo, al progresivo incremento de las aplicaciones asociadas al desarrollo de la telefonía móvil inteligente y el procesamiento de datos (Gausa, 2018; Gausa, Vivaldi, 2021).

A nivel urbano y territorial, la lectura y la articulación de una nueva condición integrada e interconectada, diversa y diversificada ("en red y en redes") iba a destacarse así como una nueva posible clave de acción asociada a la progresiva traslación de la propia noción de "red/net" (el antiguo paradigma de la ciudad neo-moderna, super-metropolitana) a la de "red/network", como nuevo dispositivo conectivo/distributivo más colaborativo, más flexible, elástico y plural para un nuevo tipo de organización decididamente "interactiva" (trenzada e interconectada); una organización en la que la noción de Multi-ciudad remitiría a una interpretación de la ciudad-región como esa nueva geo-urbanidad articulada en lo territorial (lo global) y reforzada en lo urbano (lo local). En red, en set y en net

Una dimensión "geo-urbana" que, sobre todo en escenarios de la escala y configuración matriciales de un Ramstad holandés o de un Hinterland suizo, de un Greater London o de un Grand Paris o una Grande Milano (o de la propia Barcelona-Catalunya) cobraría una dimensión prácticamente estatal o neo-regional, al manifestarse como nuevas condiciones multi-territoriales obligadas a explorar nuevos mecanismos de 
relación, no sólo más poliédricos sino, también, más "polifacéticos" en las características, en las situaciones, en las estrategias y en las respuestas a ellas asociadas (Gausa, Guallart y Müller 2003; Gausa 2009).

Uno de los objetivos fundamentales para el futuro consistiría en calibrar, entonces, si el término "metropolis" aplicado a esa nueva Barcelona/Cataluña territorial (y entendida todavía como corolario de una cierta concepción neo-industrial de expansión y de continuum urbanos, uni-jerárquicos y "mono-referenciales") no resultaría demasiado limitado ante la evidencia de un nuevo tipo de configuración supra-metropolitana (multi-urbana, clusterizada y confederada) más polifónica, discontinua y diferencial que extendería su(s) zona(s) de influencia más allá de las clásicas áreas metropolitanas, proponiendo un nuevo tipo de interpretación proactiva del territorio: la de una gran "ciudad-región", acordada a una extensa malla de superficies y relieves, de poblaciones e infraestructuras en red: una gran "ciudad de ciudades... y entre ciudades", un "paisaje de paisajes... y entre paisajes" y un "circuito de circuitos... y entre circuitos", a la vez.

Sería, éste, un escenario de intercambio plural favorecido por las grandes infraestructuras físicas y virtuales de comunicación (autopistas, trenes de alta velocidad, redes digitales de intercambio, etc.) y que, en el caso de la actual multi-Barcelona vincularía su posible desarrollo a los de Girona y Tarragona y su relación con las costas Norte y Sur en una nueva estructura multifocal (GIBARTAR) vinculada asimismo a las actuales ciudades intermedias en arcos y red combinados: MASSSTERCOM (Martorell, Sitges, Sabadell, Sant Cugat, Terrassa, Ripollet, Cerdanyola con Santa Coloma y Cornellà y el rosario de ciudades costeras del Maresme con Mataró a la cabeza) o VIGUMARRRERSOT (Valls, Vendrell, Vilanova, Vic, Igualada, Martorell, Manresa, Mataró, Granollers, Ripoll, con Reus o con Olot-Figueres, en cada extremo) y el importante potencial agro-logístico de LLEITARCER (Lleida-Tárrega-Cervera) y de la zona sur del Delta del Ebro con Amposta y Tortosa a la cabeza (Gausa, Guallart y Müller 2003; Bailo y Rull 2003).

Un territorio pues -país, región, conurbación, meta-polis, etc.- interpretado, en definitiva, como una gran supra-metrópolis discontinua y que habría ido construyendo los mimbres de su posible implementación contemporánea a lo largo de su propia historia, en una constante voluntad de distribuir y trenzar urbanidades y territorialidades a través de trazados, mallas y circuitos diversos de conexión, combinada con una distribución poblacional sensiblemente regular y secuencial, de ciudades -grandes, medias e intermedias- y una clarísima estructura geográfica entre bandas, relieves y depresiones paralelos al mar y corredores verticales, transversales, en una implícita grid geo-estructural con planas o llanos regularmente alternos, situados entre grandes macizo topográficos.

La conformación de la propia geografía catalana, la distribución y proximidad de sus principales poblaciones motoras así como su buen mallado infraestructural y eco-estructural y la implantación favorecedora de las nuevas redes de colaboración y comunicación permitirían concebir esa Barcelona/Catalunya (multi- y geo- urbana) tan característica de las antiguas ciudades-estado mediterráneas pero con un nuevo nivel de complejidad en la que grandes polos urbanos y ciudades medias e intermedias 
y paisajes y naturalezas in-between, deberían poder convivir concertados, a través de diversos niveles y capas de relación.

Sin embargo, en esa nueva dimensión territorial de una potencial multi-urbanidad en red, hoy asistimos de nuevo a otra clara división entre costa e interior: las infografías de las últimas elecciones demuestran esta separación bastante clarificadora entre ese territorio litoral, atractor, programáticamente mixto y cosmopolita (turístico, híbrido, portuario, intercambiador, glocal) y un interior más endógeno, local... y fundamentalmente y más autónomo y auto-referencial,

Las grandes cordilleras del litoral y el pre-litoral parecen dividir de nuevo esa BCN.CAT intercambiadora de esa $C A T^{B C N}$ reivindicadora.

Aunque muchos de los núcleos referenciales y de los grandes hitos simbólicos e históricos de la identidad catalana han tendido a ubicarse históricamente en el interior del país (iconos patrimoniales, edificios, paisajes, lugares, escenarios, etc.) los sistemas más potentes de vida e intercambio han ido agolpándose en las estrechas franjas de la costa y la pre-costa, que han asistido, así, a la progresiva presencia de las mayores ciudades referenciales y de las poblaciones productivas más nutridas; de las grandes infraestructuras de transporte (aeropuertos, puertos y estaciones de ferrocarril) y de las redes de movilidad más importantes (autopistas, autovías, carreteras, tendidos eléctricos y ferroviarios, etc.) así como de muchas de las más importantes instituciones educativas, culturales y sanitarias del país; y, desde luego, de las ofertas de ocio más frecuentadas (desde las playas a los parques temáticos o los circuitos lúdicos) en ese importante escenario medioambientalmente genuino y mestizo al mismo tiempo. Esa gravitación de la movilidad hacia una costa ensanchada tiende todavía a provocar grandes desequilibrios con el interior. La posibilidad de instrumentalizar correctamente los potenciales de los actuales sistemas en red, aprovechando procesos transversales entre polos atractores (litorales) y polos referenciales (interiores) conectados por nuevos circuitos $-\mathrm{y}$ dinámicas circulares- de retroalimentación, programación e intercambio llamadas a favorecer una mayor colaboración económica, social y cultural, es todavía un reto pendiente (Iribas 2003; Puig Ventosa 2001).

Catalunya ha sido, en efecto, desde siempre un lugar de cruces y encuentros culturales, comerciales, sociales y, también, migratorios: no sólo por un hipotético espíritu cívico de acogida sino también por la propia necesidad demográfica de equilibrar desde siempre (ya desde el siglo XVIIII) la baja natalidad endémica de la población autóctona con la llegada de poblaciones foráneas rápidamente integradas en la propia realidad e identidad del país. La tradición integradora del propio país -acogida fecunda en primera generación y asimilación plena y cohesionada en segunda- sigue respondiendo aún a dicho fenómeno revitalizador con (todavía) procesos abiertos de interacción, de decisivas implicaciones socioculturales y socioeconómicas. Sin embargo, los nuevos movimientos esencialistas o fundamentalistas empiezan a contrapesar (todavía de modo incipiente) esa vocación cosmopolita, mestiza e integradora de un país con un bajo índice de población, necesidad de mano de obra y apertura a un intercambio y una interacción generados a todos los niveles (Cabré y Pujades 1989).

Si la conjugación equilibrada entre Seny (sentido común), Rauxa (impulso radical y emo- 
cional) y Empenta (empuje ambicioso y operativo) ha sido siempre obligada para asegurar un desarrollo eficiente del país, su excesiva inclinación hacia los dos primeros factores ha tendido a conducir el país, o bien hacia la prudencia demasiado temerosa o bien hacia la temeridad demasiado imprudentes, con las consiguientes amenazas de desequilibrio social, económico, cultural o propositivo, carentes de posibles "horizontes" -o imaginarios de proyección (y “contrato") en común.

En este sentido, quizás un nuevo imaginario para esta BCN.CAT sería el de entenderse a ella misma no tanto como un anquilosado estado-país o una nación(sin)estado (términos de un pasado ya casi anacrónico y tardo-secular en sus referencias pat(ri)o-lógicas) sino como esa gran y dinámica (multi)ciudad-territorio: una nueva multi-metrópolis (con)federada, con un estatus especial a medio camino entre la ciudad-estado clásica y la hiper-polis o poli-polis contemporáneas: una posible Confederación metropolitana nacional en la que el término confederación aludiría a esa conjugación entre ciudades pero también a una asociación singular en/con el resto del país y en la que el termino nacional remitiría, de modo recíproco, tanto a la propia afirmación como nación (propia del imaginario, del sentimiento y del proceso histórico catalán) como a una adjetivación del propio conjunto multi-metropolitano, a nivel de todo el país.

Corriendo el riesgo de avanzar hipótesis inciertas, el potencial de esta nueva definición "multi-metropolitana" sería doble, emocional y económica: por un lado, al proponerse como una singularidad de "otra naturaleza", aceptable por las otras comunidades autónomas del resto del estado. Por otro, al asumirse una nueva condición geográfica y urbana "en común” -excepcional y estimulante- a nivel territorial/poblacional/social; una posible (re) definición con una gestión más autónoma de los recursos propios al reformularse -en esta circunstancia- un nuevo tipo de compromiso entre impuestos estatales y multi-municipales (de fondo y reparto común), capaz de favorecer nuevas ecuaciones diferenciales en las que aunar asimetría y respeto solidario -y activo"entre" comunidades propias (con competencias supra-municipales y reparto de plusvalías) y "hacia" comunidades externas; (Nel.lo 2001; Puig Ventosa 2001; Pradel 2016).

Impulsando, en cualquier caso, con resolución y ambición innovadoras campos económicos (y culturales) competitivos, con una base suficientemente anclada en la tradición local y un nuevo impulso creativo (Ciencias de la Salud, Biología y Genética, Farmacia, Diseño Inteligente, Nuevas Tecnologías, Robótica, Inteligencia Artificial y Nanotecnología, Arquitectura y Urbanismo Avanzados, Alimentación y Gastronomía, Turismo, Ciencias Audiovisuales y Escenográficas, Música Avanzada, etc.).

De hecho, si la fuerza de una región depende, en buena parte, de su capacidad para acumular intercambio, conocimiento y atractividad, la fórmula 3I+3D (esto es Investigación, Innovación, Integración + Desarrollo y Difusión y Disfrute o Deleite/Delight), resulta cada vez más decisiva a la hora de liderar procesos significativos y significantes, proyectados hacia al exterior. Factores que deberían combinarse asimismo con las $9 \mathrm{~T}$ básicas $(3 \mathrm{~T}+3 \mathrm{~T}+3 \mathrm{~T})$ de los nuevos escenarios "referenciales": las 3T definidas por Richard Florida (Tolerancia, Talento, Tecnología) conjugadas con las otras 3T definidas por Intelligent Coast (Territorialidad, 

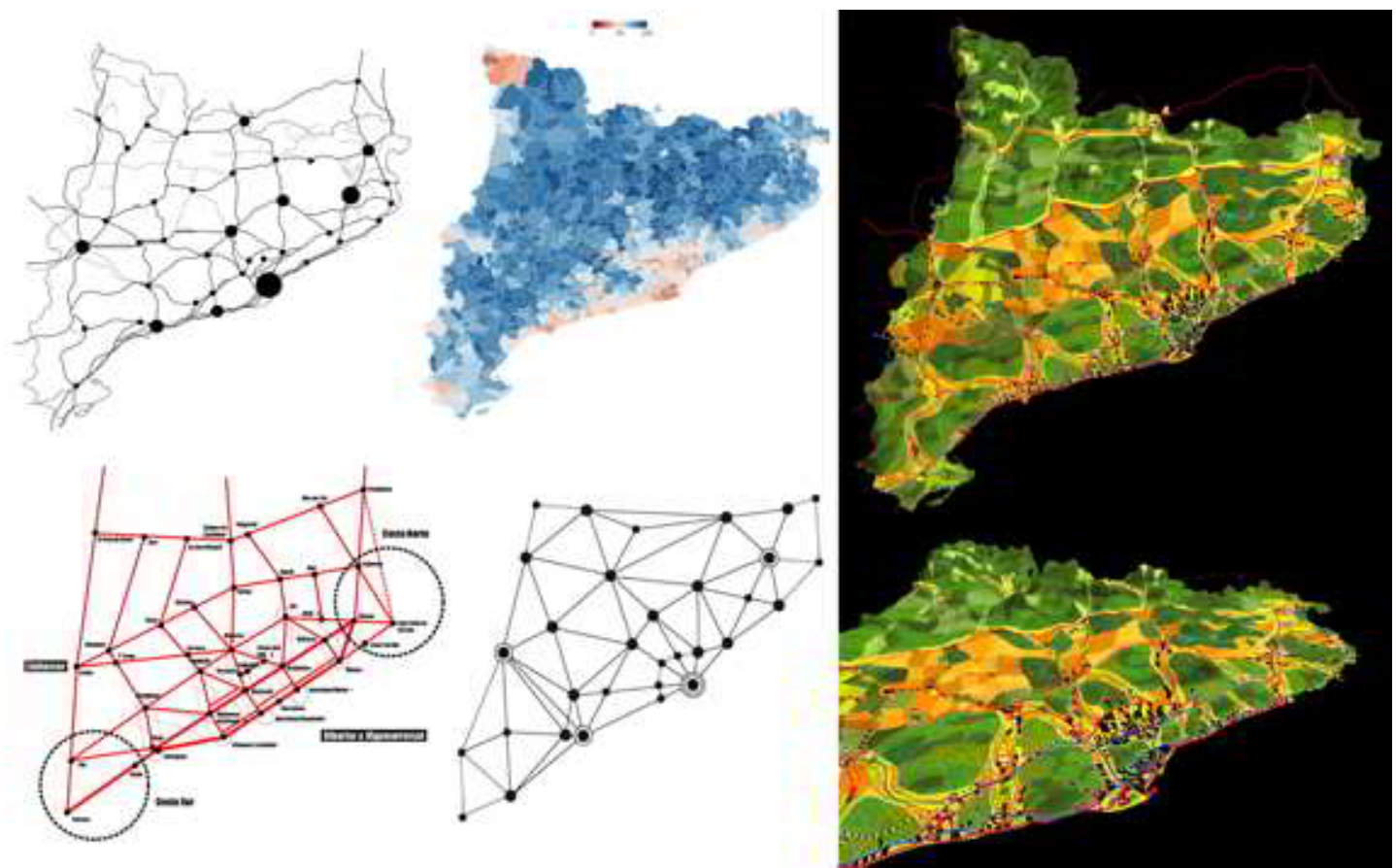

Fig. 6. BCN.CAT: Barcelona/Catalunya en red y en redes: Multi-ciudades y geo-urbanidades

Derecha. Barcelona y Catalunya como una ciudad de ciudades, un paisaje de paisajes y un circuito de circuitos, en red y en redes (Catalunya Land-Grid, Actar Arquitectura, 2003).

Izquierda arriba. Diagrama de la malla de poblaciones y núcleos en red (Catalunya Land-Grid, Actar Arquitectura, 2003) / Izquierda abajo. Diagrama "la bicicleta”: GIBARTAR, VIGUMARRRERSOT, MASSSTERCOM (Catalunya Land-Grid, Actar Arquitectura, 2003).

Centro arriba. Infografía de las elecciones de 2020 en Catalunya. Divisiones evidentes entre Costa-Pre-Costa e Interior, vocación federalista y vocación soberanista, sensiblemente separadas por las cordilleras del litoral y el pre-litoral (archivo). Diagrama de Catalunya como una Ciudad de Ciudades (Pradel, 2017).

Turismo, Tiempo) y un último trinomio fundamental (Transmisión/Thinking, Transferencia y Transversalidad (Florida 2002; Iribas 2003; Carta 2007; Gausa, Banchini y Falcón 2011).

Ciudades y territorios han sido lanzados, hoy, a un nuevo tipo de deriva en la que se multiplican las relaciones de y en red (económicas y también transculturales) más allá de los antiguos límites locales. Su capacidad de desarrollo depende fundamentalmente de su eficaz pertenencia a tales estructuras pero, sobre todo, de su capacidad para, desde el intercambio, la interacción y la interconexión, "generar" escenarios referenciales capaces de identificarlos como puntos nodales del sistema, es decir como polarizadores y distribuidores de información (de energía creativa y no sólo productiva) más que como puntos de conflicto y división, de frustración o de ensoñación hacia un pasado mejor "añorado" o "idealizado". 
En este último caso éstas se ovillan, entran en dinámicas de inercia y rutina, de auto-referencia o autocomplacencia y tienden a la auto-decadencia, esto es a una dependencia, en mayor o menor grado, sucursalista, importadora de conocimientos más que generadora de referentes.

\section{REFERENCIAS}

Aibar, Eduardo. 1995. "Urbanismo y estudios sociohistoricos de la tecnología: el caso del Ensanche de Barcelona”. Revista Llull. Vol 18: 5-33.

Ariño, Enrique, Gurt, Josep M. y Palet, Josep M. 2004. El pasado presente. Arqueología de los paisajes en la Hispania romana. BarcelonaSalamanca: Universidad de Salamanca Universitat de Barcelona.

Ariño, Enrique, Gurt, Josep Maria y Palet, Josep Maria. 1994. "El estudio de los catastros rurales: una interpretación estratigráfica del paisaje”. Revista Zephyrus (Salamanca) 47: 189-217.

Bailo, Manuel y Rull, Rosa. 2003.

"VIGUMARRERSOT: the intermediate cities”. HiperCatalunya, Territories of Research editado por Manuel Gausa, Vivente Guallart, Willy Müller. Barcelona: Generalitat de Catalunya, Actar.

Bohigas, Oriol. 1986. Reconstrucción de Barcelona. Madrid: Servicio de Publicaciones, Secretaría General Técnica, Ministerio de Obras Públicas y Urbanismo.

Braungart, Michael y Mac Donough, William. 2003. Cradle to Cradle. New York: Farrar, Straus and Giroux.
Busquets, Joan. 2006. Barcelona: la construcción urbanística de una ciudad compacta. Barcelona: El Serbal.

Cabré, Anna y Pujades, Joana. "La població: immigració i explosió demogràfica”. Història econòmica de la Catalunya contemporània, editado por Jordi Nadal, Jordi Maluquer, Carles Sudrià y Francesc Cabana. Barcelona: Enciclopèdia Catalana, vol. 1.

Carta, Maurizio. 2007. Creative Cities. Trento: List Lab.

Florida, Richard. 2002 [2014]. The rise of the creative class. New York: Basic Books.

Gausa, Manuel, Guallart, Vicente y Müller, Willy. 2003. HiperCatalunya, Territories of Research. Barcelona: Generalitat de Catalunya, Actar.

Gausa, Manuel. 2009. Multi-Barcelona, HiperCatalunya. Estrategias para una nueva GeoUrbanidad, Trento: List Lab.

Gausa, Manuel, Banchini, Silvia y Falcón, Luis. 2011. Multirambles - BCN 6T. RomaTrento: List.Lab: 1 - 278.

Gausa, Manuel, Cervelló, Marta, Plà, Maurici y Devesa, Ricardo. 2013. Barcelona Guia de Arquitectura Moderna. Barcelona: Actar. 
Gausa, Manuel (Leone, Sabrina, ed.). 2017.

Habi(li)tar, Vivienda más x menos.

Barcelona: LIST Lab.

Gausa, Manuel. 2018. Open(ing), Space-TimeInformation \& Advanced Architecture 1900-2000. The Beginning of Advanced Architecture. New York: Actar Publishers.

Gausa, Manuel y Vivaldi, Jordi. 2021. The Threefold logic of Advanced Architecture. New York: Actar Publishers.

Harvey, David. 1985. The Urbanisation of Capital. Baltimore: Johns Hopkins University Press.

Iribas José Miguel. 2003. "The Catalonias”. HiperCatalunya, Territories of Research. Editado por Manuel Gausa, Vicente Guallart y Willy Müller. Barcelona: Generalitat de Catalunya, Actar.

Llop, Carles.2011. "De les solucions habitacionals a la construcció social de l'hàbitat. Del dret a l'habitatge al dret al plaer d'habitar". Cap a un Habitatge Sostenible, editado por Manuel Gausa. Barcelona: CADS.

Maluquer, Jordi. 1994. "La gran transformació. Industrialització i modernització a la Catalunya del segle XIX". Història econòmica de la Catalunya contemporània. editado por Jordi Nadal, Jordi Maluquer, Carles Sudrià y Francesc Cabana. Barcelona: Enciclopèdia Catalana (Vol. 1).

Muñoz, Francesc. 2016. Urbanalizacion: paisajes comunes, lugares globales. Barcelona: Gustavo Gili.

Nel.lo, Oriol. 2001. Ciutat de ciutats, reflexió sobre el procés d'urbanització a Catalunya. Barcelona: Ampuries.
Pascual i Domènech, Pere. 1999. "Ferrocarriles y crecimiento económico". Siglo y medio del ferrocarril en España, 1848-1998: Economía, industria y sociedad, editado por Javier Vidal Olivares, Miguel Muñoz Rubio, Jesús Sanz Fernández. Alicante: Diputación Provincial de Alicante, Instituto Alicantino de Cultura.

Pradel, Miquel.2016. El Municipalisme de Pasqual Maragall i la seva influència en la Governança de Catalunya. Barcelona: Fundació Maragall.

Prieto, Gonzalo. 2017. "La evolución del mapa de Barcelona a través de los siglos". https:// www.geografiainfinita.com/2017/05/ la-evolucion-de-barcelona-a-traves-de-losmapas/

Puig Ventosa, Ignasi. 2011. "Polítiques econòmiques locals per avançar cap a formes més sostenibles d'habitatge i d'ocupació". Cap a un Habitatge Sostenible, editado por Manuel Gausa. Barcelona: CADS

Ricci, Mosé. 2012. Nuovi Paradigmi. Trento: List Lab.

Rifkin Jeremy. 2014. The Zero Marginal Cost Society: The Internet of Things, the Collaborative Commons, and the Eclipse of Capitalism. London: Palgrave Macmillan.

Rueda, Salvador. 2011. "Models d'ordenació del territori més sostenibles (o un nou urbanisme per a abordar els reptes de la societat actual)". Cap a un habitat(ge) sostenible, editado por Manuel Gausa. Barcelona: CADS. 
Solà-Morales, Manuel. 2008. Diez lecciones sobre Barcelona. Barcelona: Col-legi d'Arquitectes de Catalunya.

Solà-Morales, Manuel. 2010. Cerdà: ensanche . Barcelona: Ediciones UPC.

Solà Morales, Ignasi. 2002. Territorios. Barcelona: Gustavo Gili.

Manuel Gausa (Barcelona 1959), Doctor arquitecto, desde 2017 Catedrático de Urbanismo y Proyectos Urbanos (DAD-Dipartimento di Architettura e Design - UNIGE, Università degli Studi di Genova) y Director-coordinador del ADD-Doctorado en Arquitectura y Design en la propia UNIGE

Co-fundador y Dean (2012-2015) del IAAC-Institut d'Arquitectura Avançada de Catalunya, Barcelona, actualmente es Lead Professor in Advanced Knowledge Theory y Miembro del Comité Científico

Fundador del grupo Actar y del estudio Gausa-Raveau actarquitectura. de Soto, Pau y Carreras, Cesar. 2007. "Anàlisi de la xarxa de transport a la Catalunya romana: alguns apunts". Revistad' Arqueologia de Ponent (Lleida), 16-17: 177.

Autor de numerosas publicaciones. Sus intereses de investigación se focalizan en temas de prospectiva urbano-territorial y en los ámbitos de la arquitectura y el paisaje come sistemas -y dispositivos-multi-escalares así como en las nuevas teorías de la complejidad referidas a una nueva Lógica Informacional.

Autor de numerosos libros, artículos y publicaciones, sus proyectos han sido galardonados con numerosos premios internacionales. En 2000 fue distinguido con la Medaille de l'Académie d'Architecture de France. 


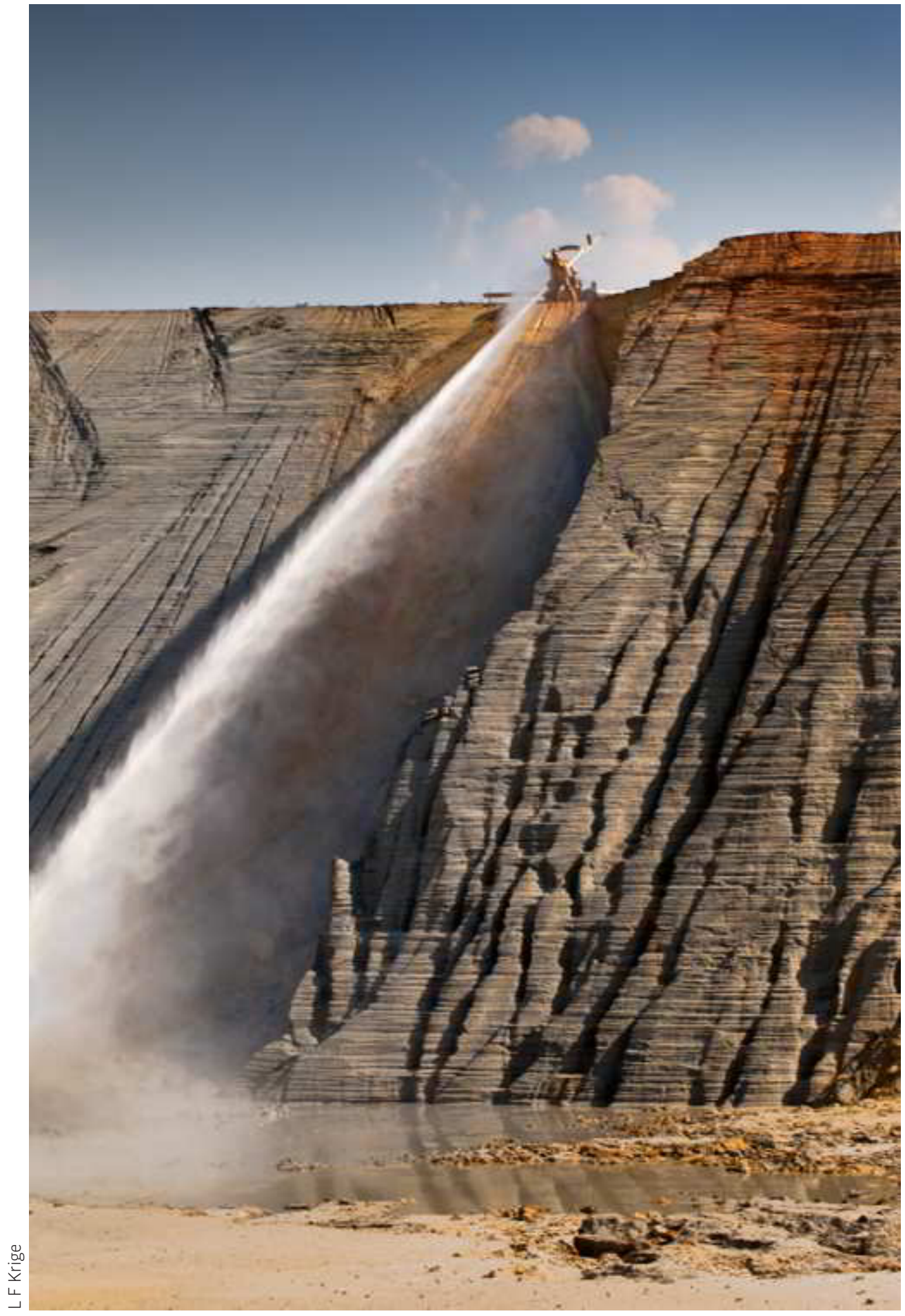




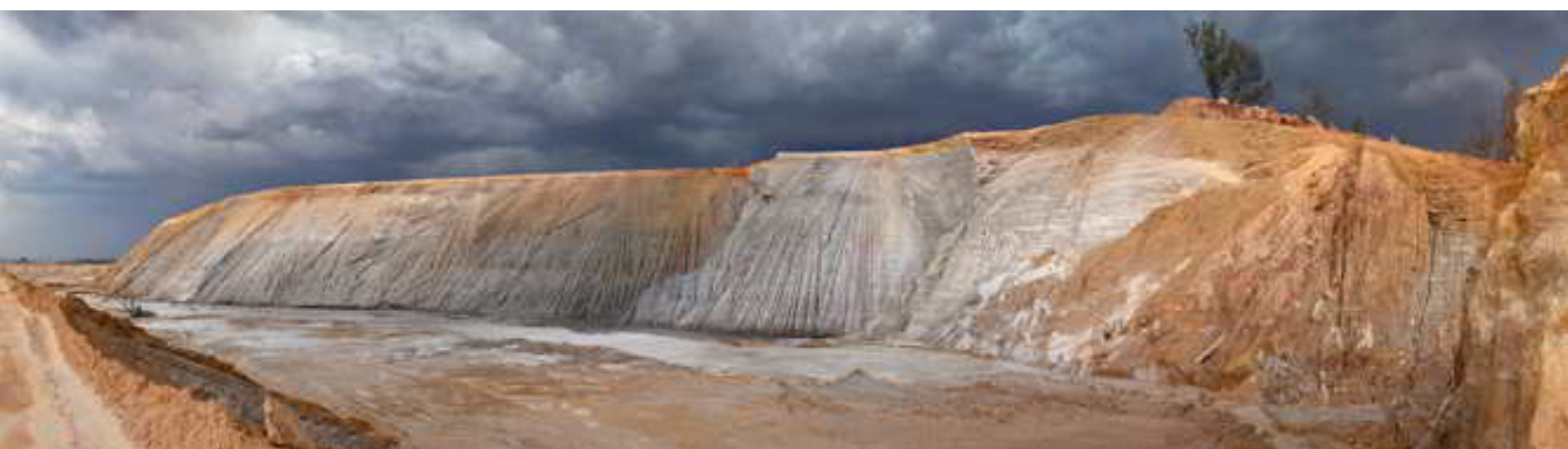

L F Krige 